Samuel Fernández E.

Profesor Facultad de Teología

Pontificia Universidad Católica de Chile

\title{
El carácter universal, único y definitivo de Jesús de Nazaret en los inicios de la cristología
}

\section{INTRODUCCIÓN \\ 1. Aclaración inicial}

Enfrentar el tema del carácter "absoluto" de Jesús resulta problemático, pues este concepto parece ajeno al lenguaje de la Iglesia del Nuevo Testamento. Si consideramos que "absoluto" significa, en su primera acepción, según el diccionario de la RAE, "que excluye toda relación", entonces, estrictamente, no lo podemos aplicar a ninguna de las personas de la Trinidad que, según la definición clásica, son relaciones subsistentes.

En términos estrictos, el Hijo, que es proexistente tanto en la economía como en la vida trinitaria (1), está por definición referido a Otro y, por tanto, en sentido estricto es contradictorio hablar del "Hijo" en sentido "absoluto", puesto que hijo es un término relativo a padre (2). Lo mismo se debe decir de Jesús en la economía. Los términos Salvador o Mediador están por definición referidos a otros y, por tanto, estrictamente, es contradictorio hablar del Salvador "absoluto" o del Mediador "absoluto", puesto que ambos son términos que hacen referencia a otro. Así, ni en la economía ni en la inmanencia trinitaria se puede aplicar, en términos estrictos, el concepto "absoluto" a Jesucristo. Distinto es el caso si se comprende "absoluto" en el sentido de indeterminado, incondicionado, universalmente válido.

Entonces, considerar "absoluto" y "relativo" como conceptos contrarios no es coherente con la revelación trinitaria. El mismo concepto de "Gracia” incluye lo "absoluto", en sentido de indeterminado, pues el don no está motivado por los méritos, y lo "relativo", pues es autocomunicación, que no se basta a sí misma y siempre está referida a otro. Al parecer, los conceptos "absoluto" y "relativo" no

(1) Cf. H. Schürmann, El destino de Jesús: Su vida y su muerte, Sígueme, Salamanca 2003.

(2) Esta afirmación presente en la teología trinitaria contemporánea, fue desarrollada en torno a Nicea. San Alejandro de Alejandría, para defender la coeternidad del Hijo respecto del Padre, argumenta que si Dios es Padre desde siempre, entonces debió tener desde siempre un Hijo, pues padre e hijo son términos relativos. Cf. Alejandro de Alejandría, Carta II, 25, en Teodoreto, Historia Eclesiástica I, 4; Arrio, Carta a Eusebio de Nicomedia, en Epifanio, Haer., LXIX, 6. 
han sido aún suficientemente revisados, ampliados y reajustados a la luz de la revelación trinitaria y de la ontología que se desprende de ella.

¿Qué sentido tiene, entonces, el tema que estamos tratando en nuestro Seminario? Tiene sentido si el discurso sobre el carácter "absoluto" de la cristología lo comprendemos como una afirmación del significado "universal”, "único" y "definitivo" de Jesús (3). Lo que se pretende, entonces, es afirmar que la revelación histórica de Dios en Jesús de Nazaret es "universalmente válida” y que, por tanto, el Señor Jesús es Salvador y Mediador universal, único y definitivo. De hecho, la declaración Dominus Iesus lleva por título "Declaración sobre la unicidad y la universalidad salvífica de Jesucristo y de la Iglesia", y en ella no se insiste en el carácter "absoluto" del Señor Jesús.

\section{Planteamiento del problema}

Hoy, como nunca, creemos haber tomado conciencia de la amplitud del mundo y de la diversidad de las culturas. Ante esta gran variedad de modos de concebir a Dios, la vida, el hombre y el mundo, que conviven en una sociedad global cada vez más conectada (al menos en algunos aspectos), surge una cierta incomodidad al proclamar a Jesús de Nazaret como Salvador único, universal y definitivo (4). Esta convicción se presenta como una característica singular del cristianismo y, a la vez, a una primera mirada, como "la fuente principal de dificultades en el momento de relacionarse con otras religiones", y el mayor escollo para un diálogo franco, de igual a igual, con la sociedad plural. Por ello, algunos hablan de una "desabsolutización la cristología” (5).

Esto nos hace preguntarnos: ¿Cuándo surgió en el cristianismo la pretensión de universalidad? Algunos han dicho que solo con el apoyo de Constantino y luego de Teodosio el cristianismo adquirió conciencia de universalidad de su mensaje y se volvió intolerante (6). ¿Hay, en este caso, una relación causalefecto entre la situación política de la Iglesia y sus convicciones teológicas? Dicho de otro modo, ¿la pretensión de universalidad de la fe cristiana es una consecuencia de su nueva situación en el Imperio? Si esto fuera así, esta pretensión sería un dato negociable ante el nuevo contexto social en que hoy se encuentra la Iglesia.

El presente artículo no pretende elaborar una teología de las religiones o ensayar una respuesta al difícil tema del significado de Jesucristo en las demás experiencias religiosas. La presente exposición tiene un objetivo más modesto: intenta abordar históricamente la siguiente pregunta: ¿Cuál es el origen y alcance de la pretensión cristiana que proclama a Jesús de Nazaret como Salvador único, universal y definitivo? Es decir, busca aportar ciertas bases necesarias, con una perspectiva

(3) En este sentido, muchos teólogos usan legítimamente el término “absoluto". En la presente ponencia, para evitar malos entendidos, hablamos de "universal", "único" y "definitivo".

(4) Cf. M. de França Miranda, Jesucristo y el diálogo de las religiones, en M. González et ali, El misterio de la Trinidad en la preparación del gran jubileo, Buenos Aires 1998, pp. 99-140.

(5) Cf. M. de França Miranda, Jesucristo y el diálogo de las religiones, p. 105; R. Bernhardt, Deabsolutierung der Christologie?, en M. von Brük - J. Werbick, Der einzige Weg zum Heil? Quaestiones disputatae, Freiburg 1993, pp. 144-200.

(6) Cf. P.F. Beatrice (ed.), L'intolleranza cristiana nei confronti dei pagani, Bologna 1990. 
historicodogmática, desde las cuales se pueda reflexionar acerca de la teología cristiana de las religiones.

Para el desarrollo de este tema es necesario tener en cuenta que los conceptos de "único", "universal” y "definitivo" de algún modo se reclaman mutuamente (7).

\section{DESARROLLO HISTÓRICO}

\section{Cristianismo preniceno}

No es necesario demasiado espacio para probar que la pretensión de universalidad ya se encuentra bien atestiguada en el cristianismo preniceno. Tanto el sistema valentiniano (8), como la teología de la recapitulación en Ireneo (9), son testigos de la pretensión universalista y omniabarcante de la revelación cristiana. Las obras de los apologistas, por su parte, buscan la conversión de todos al cristianismo y, por eso, son discursos misioneros de perspectiva universal (10). La doctrina de las "semillas del Logos" de Justino, un autor que valoró como pocos la cultura imperial, afirma que todo el género humano participa del único Logos divino, que solo se encuentra plenamente en Jesús de Nazaret, y que el resto son manifestaciones parciales del único Logos (11).

La universalidad y unicidad de la función del Logos queda además asegurada por su participación en la obra de la creación. Teófilo de Antioquía declara que el

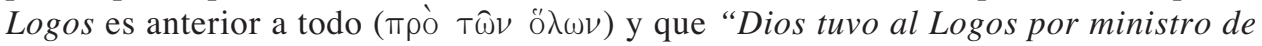

(7) La universal voluntad salvífica de Dios implica que su autocomunicación definitiva debe tener un alcance universal y, a su vez, el carácter definitivo, y por ello exhaustivo, de la revelación reclama su unicidad. La reciprocidad de los conceptos en cierto sentido es circular.

(8) El interés universalista de la teología valentiniana se manifiesta de modo agudo en unas palabras de Ptolomeo que delatan su propia preocupación: "De momento no te preocupe demasiado esto,

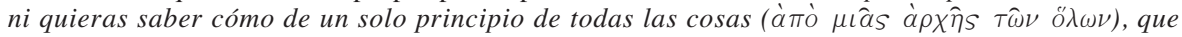
es, según confesamos y creemos, simple, ingénito, incorruptible y bueno, pudieron venir a la existencia naturalezas como aquellas, a saber la de la corrupción y la de la Mediedad, ambas de sustancia diversa, siendo propio de la índole del bueno engendrar y emitir seres semejantes y consubstanciales a sí mismo”, Ptolomeo, A Flora, 7, 8 (apud Epifanio).

(9) Ireneo insiste en que hay un único proceso salvífico que va desde la creación hasta la consumación final. Este proceso es universal pues abarca la carne y el espíritu, el AT y el NT, al Dios Creador y al Salvador, etc. Cf. Adversus haereses, I, 10, 3, 56-57; III, 16, 6, 210-223; V, passim. R. Polanco, El concepto de profecía en la teología de san Ireneo, Madrid 1999, pp. 387-394.

(10) Cf. J. Daniélou, Message Évangélique et culture hellénistique aux IIe et IIIe siècles, Tournai 1990, pp. 11-19. La conciencia de universalidad se manifiesta también al afirmar que Jesús juzgará a toda la humanidad, cf. Justino Apol., II, XV, 2-4; Arístides, XVII, 3-4. 8.

(11) Apol., I, 13, 4. Cf. "Nosotros hemos recibido la enseñanza de que Cristo es el primogénito de Dios, y hemos indicado que Él es el Logos, del que ha participado todo el género humano (Tầ $\gamma \in \nu O S \alpha \dot{\alpha} \theta \rho(\dot{\pi} \pi \omega \nu)$. Así, quienes vivieron conforme al Logos, son cristianos, aun cuando fueron tenidos por ateos [...] y los que vivieron sin Logos, son inútiles, enemigos de Cristo y asesinos de quienes viven de acuerdo al Logos" (Apol., I, 46, 2, cf. Apol., I, 13, 4). "Y es que los escritores todos solo oscuramente pudieron ver la realidad gracias a la semilla del Logos en ellos ingénita. Una cosa es, en efecto, el germen e imitación de algo que se da conforme a la capacidad, y otra aquello mismo cuya participación e imitación se da, según la gracia que de aquel también procede" (Apol., I, 13, 6). 


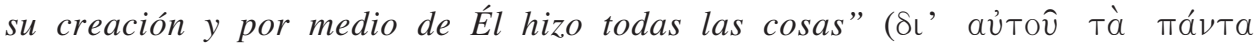
$\pi \in \pi \circ \operatorname{li}_{\uparrow \in \in \nu)}$ (12). En términos semejantes se expresa Atenágoras (13).

Pero la pretensión cristiana de proclamar una verdad universal y definitiva, ¿se hizo presente solo en los sectores cristianos más instruidos o perteneció a la predicación primitiva?

En base a la obra de Celso, escrita en torno al año 178, se puede tener una idea de la predicación del cristianismo popular. El filósofo pagano rechaza que un acontecimiento específico, en un momento puntual, en un rincón de la tierra, por medio de un único mensajero, pueda tener relevancia universal (14). Si Dios quería revelarse, debió abarcar toda la tierra homogéneamente. Celso afirma que Dios es Padre

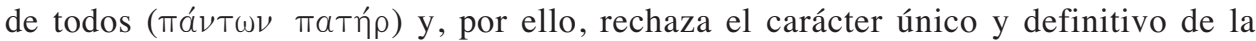
revelación en Jesús de Nazaret (15). Si el Dios único se manifiesta en la historia, entonces la libertad de Dios es caprichosa y arbitraria (16). El carácter universal, único y definitivo de la pretensión cristiana se confirma por las amenazas de castigos eternos que lanzan los predicadores contra todos los que no adhieran a la doctrina de Jesús, amenaza que involucra a todo el género humano (17). Se trata, en parte, de la misma objeción de G.E. Lessing, ya mencionada en este Seminario: "Las verdades históricas contingentes nunca pueden ser demostración de verdades necesarias" (18).

Esta polémica y estas afirmaciones son testimonio indirecto de la conciencia eclesial de poseer una verdad incompatible con las religiones paganas. El cristianismo, tal como el judaísmo, excluía a las demás religiones (19). De este modo, la

(12) Teófilo de Antioquía, A Autolico, II, 10; cf. II, 22.

(13) Atenágoras de Atenas, Legatio, X, 1-2: “Todo ha sido hecho, ha sido ordenado y se conserva, por medio de su Logos [...]. Pues conforme a Él [el Logos] y por Él todo fue hecho”. Cf. VI, 2.

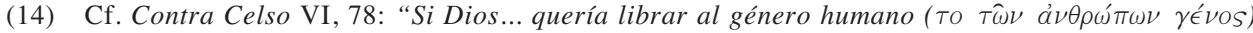

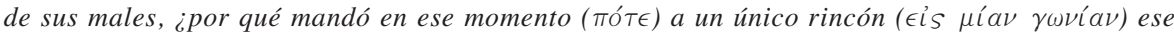
espíritu que decís? Más bien debiera haber soplado igualmente en muchos cuerpos y haberlos enviado por toda la tierra”; IV, 7: “¿Acaso [solo] ahora-objeta Celso-, después de [todos] estos siglos, Dios se acordó de juzgar la vida de los hombres que, anteriormente, por el contrario, desatendía?".

(15) Celso está dispuesto a aceptar que Jesús sea un ángel, pero niega que sea "el primero o el único", y rechaza la predicación cristiana que exhorta "a creer solo en Jesús”, cf. Contra Celso VIII, 14; VIII, 11; VIII, 15; V, 52; VI, 42.

(16) "The nerve-center of the debate between Origen and Celsus lies in the possibility of revelation in history... To Celsus the Christian doctrine means that God's freedom is arbitrary and capricious" H. Chadwick, Early Christian Thought and the Classical Tradition, Oxford 1966, p. 120. Cf. M. Fédou, Christianisme et religions païennes dans le Contre Celse d'Origène (Théologie Historique 81), Paris 1988, pp. 536-537.

(17) Cf. Contra Celso IV, 10; VIII, 48; además VII, 9. Según Celso, judíos y cristianos creen que "cuando Dios traiga el fuego, todo el género humano quedará quemado y solo ellos sobrevivirán” (V, 14). Este exclusivismo tiene consecuencias eclesiológicas: los cristianos, según Celso, pretenden ser los únicos beneficiarios de la acción de Dios. A Celso le parece inconcebible que un grupo tan miserable como los cristianos se considere a sí mismo como el único destinatario de la providencia y de la revelación divina (cf. IV, 23; III, 75).

(18) G.E. Lessing, Über den Beweis des Geistes und der Kraft, en Werke VI, Frankfurt 1965, p. 285 (citado por H. Waldenfels, Teología fundamental contextual, Salamanca 1994, p. 218). Cf. E. Schillebeeckx, Jesús. La historia de un viviente, Madrid 1983, pp. 549-551.

(19) "El cristianismo desplegó un carácter más duro y más duradero basado en una convicción más profunda que otras religiones de poseer la verdad”, R.P.C. Hanson, The Christian Attitude to Pagan Religions up to the Time of Constantine the Great, en H. Temporini-W. Haase (Eds.), 
afirmación de Jesús como Salvador único y universal está presente en los autores más antiguos, e incluso se puede rastrear en la misma regla de fe (20). Todo esto nos lleva, como es lógico, al Nuevo Testamento.

\section{La pretensión cristiana en el Nuevo Testamento}

La pretensión cristiana de proclamar, en Jesús de Nazaret, una verdad universalmente válida y definitiva se encuentra documentada en el Nuevo Testamento. Se expresa de modo radical en aquellos textos que vinculan la universalidad salvífica de Cristo con su función, también universal, en la obra de la creación.

La fe veterotestamentaria en la creación forma parte de la herencia que el cristianismo recibió del judaísmo. Dios es el creador de todo: "Tú has creado el universo; por tu voluntad, no existía y fue creado" (Ap 4, 11, cf. Heb 11, 3; Rom 4, 17). Pero la especifidad del Nuevo Testamento, a este respecto, reside en la función que atribuye a Cristo en la obra de la creación (21). No corresponde desarrollar directamente la relevancia de Cristo en la obra de la creación; esta doctrina interesa en la medida en que es una afirmación radical del significado único y universal de Cristo. Sin afán de exhaustividad ni de entrar en las dificultades de cada texto, revisamos aquellos más relevantes para nuestro propósito.

a. La Carta a los Hebreos, valiéndose del lenguaje sacerdotal, afirma que en Jesús se da "realmente una comunicación perfecta y definitiva entre el hombre $y$ Dios” (22). El tema central es soteriológico, pues gira en torno a la universalidad salvífica de Cristo. Esta universalidad soteriológica tiene su fundamento en la universalidad creacional: el Hijo que es el Heredero de todo es también por

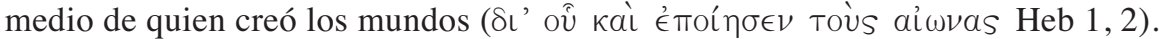

b. El prólogo de Juan también afirma el carácter cristológico de la creación (23). El evangelio presenta a Jesús como el revelador único y definitivo del Padre: "A Dios nadie le ha visto jamás: el Hijo único, que está en el seno del Padre, él lo ha contado" (Jn 1, 18); "Nadie va al Padre sino por mí” (Jn 14, 4; cf. 6, $44 ; 6,65)$. La pretensión de universalidad y exclusividad salvífica, encuentra

Aufstieg und Niedergang der römischen Welt, II, Principat, XXIII/2, Berlin-New York 1980, pp. 959-960. Por ejemplo, en el año 180, durante el proceso de los mártires escilitanos, el procónsul Saturnino afirma que la religión de los cristianos "consiste en vilipendiar nuestra religión" (Actas de los mártires escilitanos, 5). Cf. G. Bardy, La conversión al cristianismo durante los primeros siglos, Madrid 1990, pp. 83-85.

(20) Cf. Hermas, El Pastor, Sim., IX, 12; Clemente romano, Carta a los Corintios, 46, 6; Ireneo de Lión, Adversus haereses, I, 10, 1; Adversus haereses, V, 20, 1; Demostración, 6; Tertuliano, De praescriptione haereticorum, XIII. 1-6; Adversus Praxean, II, 1; Cipriano de Cartago, Carta 69, 7. B. Studer, Dio Salvatore nei Padri della Chiesa, Roma 1986, pp. 55-57.

(21) Cf. J. Noemi, El mundo, creación y promesa de Dios, Santiago 1996, pp. 74-87; C.E. Gunton, The Triune Creator. A Historical and Systematic Study, Michigan 1998, pp. 20-24. 41-44.

(22) A. Vanhoye, Sacerdotes antiguos, sacerdote nuevo en el Nuevo Testamento, Salamanca 1984, p. 218. Cf. B. Sesboüé, Jesucristo el único mediador. Ensayo sobre la redención y la salvación, Salamanca 1990, pp. 100-104.

(23) Cf. L.W. Hurtado, Lord Jesus Christ. Devotion to Jesus in Earliest Christianity, Eerdmans 2003, pp. 349-407; R. Schnackenburg, La persona de Jesucristo reflejada en los cuatro evangelios, Herder 1998, pp. 359-420. 
su fundamento en la identidad de Jesús, que es el Unigénito de Dios, y que en la obra de la creación: "todo ha sido hecho por medio de Él” (

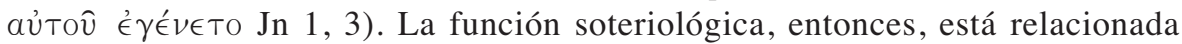
con la persona de Jesús (en su identidad). Tal como afirma Schnackenburg, "la persona salvífica y la función salvífica se halla inseparablemente unidas" (24). De este modo, se relaciona soteriología con ontología; puesto que la 'función' soteriológica de Jesús se fundamenta en el 'ser' salvífico de Jesús y además en el 'ser' capax salutis de la creación (puesto que la creación es rà ¿́sı Jn 1, 11) (25).

c. El cántico de Colosenses 1, 15-20 presenta a Cristo como aquel en quien han

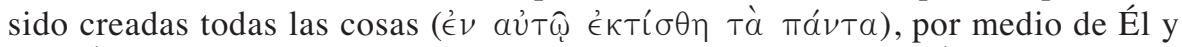
para Él han sido creadas todas las cosas (Tà rávTa) (26), en Él tienen consistencia todas las cosas ( $T \grave{a} \pi \alpha ́ v T \alpha)$ y en quien y por quien han sido reconciliadas todas las cosas ( $\tau \grave{a} \pi \alpha ́ v \tau \alpha)$. La relevancia universal de Jesucristo queda bien expresada por el cuádruple Tà тá $\nu \tau \alpha$ del cántico: todo está llamado a ser reconciliado por Cristo y en Cristo, pues todo se sostiene en Él, dado que en Él fueron creadas todas las cosas. Lo que se piensa en orden deductivo (creación, sostenimiento y reconciliación) posiblemente fue razonado en orden inverso (reconciliación, sostenimiento y creación). En la reflexión cristiana primitiva, el orden noético precede al orden del ser.

El interés central de los textos que afirman la cristología cósmica es soteriológico. Es decir, a partir de la preocupación por comprender el alcance universal del plan salvífico de Dios en Cristo, se llega a la vinculación de Cristo con la obra de la creación, lo que fundamenta de modo radical la pretensión de unicidad y universalidad de la salvación ofrecida en Cristo.

Los textos estudiados, al menos Jn 1, 1-18 y Heb 1, 1-4 pertenecen a las etapas tardías del Nuevo Testamento. El caso de Col 1, 15-20 es más complicado por un doble problema: la contestada atribución paulina de la carta y la compleja relación entre el autor de la carta y el cántico mismo (27). Por esto, para dar un paso más, nos preguntamos si en los autores más tempranos del Nuevo Testamento encontramos documentada esta pretensión de universalidad.

(24) R. Schnackenburg, La persona de Jesucristo reflejada en los cuatro evangelios, p. 322.

(25) Ptolomeo, en contra de Marción, recuerda: "el apóstol, refutando anticipadamente la inconsistente sabiduría de estos embusteros [los marcionitas], afirma que la creación del mundo es 'cosa propia', pues 'todo fue hecho por medio de él y sin él no se hizo cosa alguna', Carta a Flora, 3, 6.

(26) El texto insiste en la universalidad: "en Él fueron creadas todas las cosas, en los cielos y en la tierra, las visibles y las invisibles, los Tronos, las Dominaciones, los Principados, las Potestades: todo fue creado por Él y para Él” Col 1, 16.

(27) En todo caso, la mayoría de los estudiosos consideran el cántico como prepaulino. Cf. J.D.G. Dunn, Christology in the Making. A New Testament Inquiry into the Origins of the Doctrine of the Incarnation, Philadelphia 1980, pp. 187-188. 


\section{Textos propiamente paulinos}

En Pablo el significado universal, definitivo y único de Cristo, en lo que se refiere a la salvación, está expresado de varias maneras. No solo conceptualmente en sus textos sino que 'fácticamente' en su actividad misionera: "Raíz última de la idea de la misión es la salvación universal de los hombres que Cristo obró con su cruz y resurrección” (28). De este modo, la misión universal es la expresión pastoral de la convicción del significado universal de Jesús.

Pablo afirma que Cristo "murió por todos" (2Cor 5, 14-15) y es Señor de todos (кúplos má $\nu T \omega \nu$, Rom 10,12). La universalidad del señorío de Cristo lleva al Apóstol incluso a afirmar que Cristo es Señor de vivos y muertos (Rom 14, 9). La tipología antitética de Adán y Cristo es otro modo de expresar el alcance universal de la obra del Hijo de Dios que alcanza a toda la humanidad (29). En esta tipología, tal como el pecado de Adán, la justificación en Cristo alcanza a todos los hombres

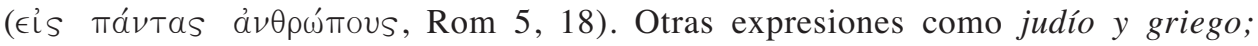
esclavo y libre; hombre y mujer, son expresiones del alcance universal de la obra de Cristo (cf. Gál 3, 28).

Un texto de gran relevancia es 1 Tim 2, 5. El pasaje no ofrece referencias cosmológicas (30), pero aborda explícitamente tanto la universal voluntad salvífica de Dios como la unicidad de la obra mediadora de Cristo:

“3 Esto es bueno y agradable a Dios, nuestro Salvador, ${ }^{4}$ que quiere que todos los

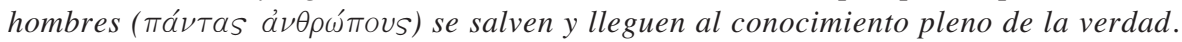
5 Porque hay un solo Dios ( $\epsilon \hat{i} s$ rà $\rho \in \epsilon o ́ s)$, y también un solo mediador ( $\epsilon \hat{i} s$ kai

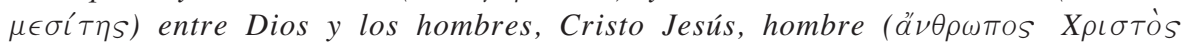

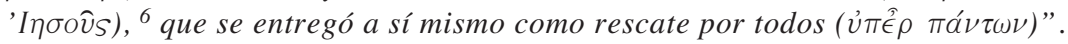

El texto destaca la unicidad de Dios y la universalidad de su voluntad salvífica (31). A la unicidad de Dios ( $\epsilon$ ís rà $\theta \in O ́ S$ ) corresponde la unicidad del Mediador entre Dios y los hombres ( $\epsilon \hat{i} S$ кai $\mu \in \sigma i ́ T \eta S$ ); y a la universalidad de la voluntad

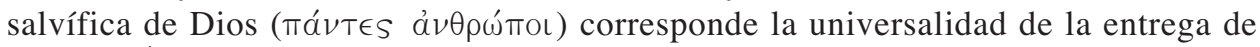

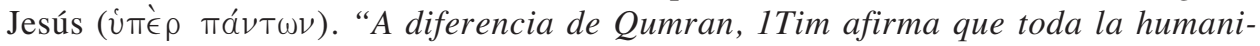
dad (no solo los elegidos) tienen un mediador que ha sido hecho del mismo polvo que Adán y que habla no solo su lenguaje sino el de Dios” (32).

(28) J. Gnilka, Pablo de Tarso. Apóstol y testigo, Barcelona 1998, p. 130.

(29) La insistencia en la universalidad de la función de Cristo es notoria: "todos revivirán en Cristo... depués de haber destruido todo Principado, Dominación y Potestad... debe reinar hasta que ponga a todos sus enemigos bajo sus pies... Porque ha sometido todas las cosas bajo sus pies... Cuando hayan sido sometidas a él todas las cosas, entonces también el Hijo se someterá... para que Dios sea todo en todo" (1Co 15, 22-28, cf. 2Co 5, 14; Rom 5, 12-21). J.G. Gibbs, Creation and Redemption. A Study in Pauline Theology, p. 57.

(30) Algunos sostienen que el término $\mu \in \sigma i ́$ T⿰S incluye también un significado cosmológico, cf. M. Dibelius and H. Conzelmann, The Pastoral Epistles, Philadelphia 1972, p. 42.

(31) Si Dios es uno solo, debe ocuparse de todos los hombres, no solo de unos pocos. Es posible que la expresión $\in \hat{i}$ $\theta \in o ́ s$ sea una fórmula tradicional. Cf. R.A. Wild, en NCBSJ, Nuevo Testamento, $56: 31$, p. 459.

(32) J.D. Quinn and W.C. Wacker, The First and Second Letters to Timothy. A new Translation with Notes and Commentary, Cambridge 2000, p. 185. 
El texto asegura que el Mediador es el hombre Cristo Jesús, afirmación que se fortalece por la alusión a la entrega sacrificial, que solo se puede referir al encarnado (33). La voluntad salvífica universal de Dios se realiza por la obra histórica de Jesús. Es decir, la universalidad salvífica y la unicidad de la mediación no pertenecen a un personaje celeste, sino a Jesús hombre, aquel que se entregó a sí mismo por todos. De este modo, el "único" Dios, que quiere que "todos" se salven, realiza su voluntad por medio del "único" Mediador, que se entregó a sí mismo por "todos”. Unicidad y universalidad están explícitamente afirmadas respecto de Dios y del Mediador.

\section{Cristianismo prepaulino}

Llegados a este punto nos preguntamos si los conceptos de unicidad y universalidad de la obra de Cristo pertenecen a la enseñanza de Pablo y Juan o provienen del primer cristianismo. La clásica Religionsgeschichtliche Schule ha insistido en que el cristianismo original no tenía esta pretensión universal, y que esta habría entrado en las comunidades junto con los conversos provenientes del helenismo y que, en este proceso, Pablo y después Juan habrían sido un factor de corrupción del cristianismo original. Ante esta sospecha es necesario buscar el material tradicional del NT, en modo de iluminar el período inicial de la Iglesia, es decir, los años anteriores a Pablo.

Los textos del NT, en su estado final, son todos posteriores a los años 50, pero contienen elementos anteriores a su redacción actual. "Casi todos los estudiosos del NT están de acuerdo que los primeros cristianos usaron material confesional... Además, la mayoría está convencido que podemos identificar al menos algo de este material al interior del NT" (34). Dicho de modo más simple, las cartas de Pablo contienen material prepaulino que es posible reconocer (35). Además, en algunos episodios de Hechos se puede reconocer mucho material tradicional.

Estudiaremos, entonces, el Cántico de Filipenses, la profesión de fe de 1Co 8, 6 y el martirio de Esteban, textos que son particularmente relevantes para nuestro presente propósito.

(33) También en Heb 8, 6; 9, 15; 12, 24, el término $\mu \epsilon \sigma i ́$ тๆs está relacionado con el lenguaje sacrificial.

(34) R.N. Longenecker, New Wine into fresh Wineskins. Contextualizing the Early Christian Confessions, Hendrickson Publishers 1999, p. 7. Para los metodos y el contenido del material tradicional, cf. V. Fusco, Le comunità cristiane. Tradizione e tendenze nel cristianesimo delle origini, Bologna 1997, pp. 61-70; R.N. Longenecker, New Wine into fresh Wineskins. Contextualizing the Early Christian Confessions, Hendrickson Publishers, 1999; R.N. Longenecker, Christological Materials in the Early Christian Communities, en R.N. Longenecker, Contours of Christology in the New Testament, Gran Rapids 2005, pp. 47-76; Ph. Vielhauer, Historia de la literatura cristiana primitiva, Salamanca 1991, pp. 23-70; una breve exposición en J. Sánchez Bosch, Escritos paulinos, Verbo Divino 1998, pp. 61-63. Según J. Dunn, estas fórmulas "pueden ser detectadas simplemante por la regularidad de su forma y por la frecuencia con que son repetidas", J.D.G. Dunn, The Theology of Paul the Apostle, p. 174.

(35) Por 'material prepaulino' se puede entender el material anterior a la conversión de Pablo (este es el material prepaulino en sentido estricto), o bien, el material anterior a las cartas de Pablo (en cuyo desarrollo y elaboración Pablo mismo pudo intervenir). 
a. Cántico de Filipenses 2, 6-11

Sin duda, uno de los textos más relevantes para conocer los primeros pasos de la cristología es el cántico de Filipenses:

2, ${ }^{6}$ El cual, siendo de condición divina, no retuvo ávidamente el ser igual a Dios.

${ }^{7}$ Sino que se despojó de sí mismo tomando condición de siervo haciéndose semejante a los hombres, apareciendo en su porte como hombre;

8 se humilló a sí mismo, obedeciendo hasta la muerte y muerte de cruz.

${ }^{9}$ Por lo cual Dios le exaltó y le otorgó el Nombre, sobre todo nombre.

${ }^{10}$ Para que al nombre de Jesús toda rodilla se doble en los cielos, en la tierra y en los abismos,

${ }^{11}$ y toda lengua confiese que Cristo Jesús es Señor para gloria de Dios Padre.

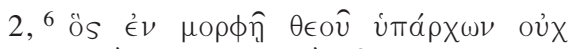

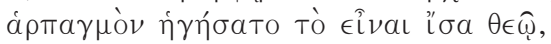

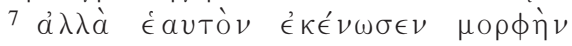

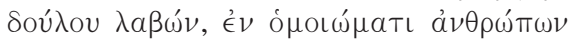

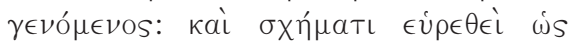
$\ddot{\alpha} \nu \theta \rho \omega \pi \mathrm{s}$

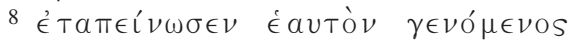

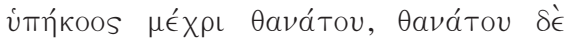
бтачpov.

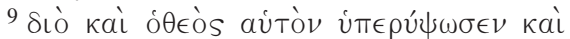

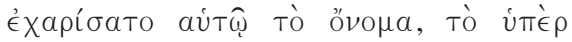
$\pi \hat{\alpha} \nu$ övo $\mu \alpha$,

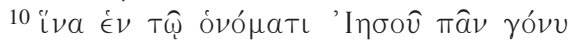

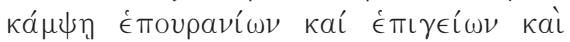
катах $\operatorname{coví\omega \nu }$

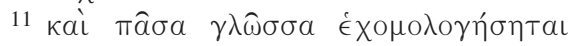

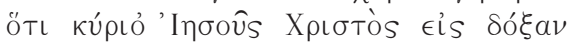
$\theta \in o \hat{~ m a t \rho o ́ s . ~}$

Por motivos bien convincentes, el texto es considerado prepaulino por la mayoría de los estudiosos y, por lo tanto, muy antiguo (36). El cántico de Filipenses nos abre, entonces, una ventana a la fe y al culto de los cristianos de los primerísimos años (37). El Preexistente, que fue humillado, ha sido exalatado y recibe la adoración de toda la creación, ubicándose así en una posición única junto a Dios, diferenciado de toda la creación. La altísima posición que recibe el Hijo no rivaliza con el Padre, pues toda la creación rinde culto al Señor Jesús "para gloria de Dios Padre”.

El texto de Isaías 45, 23, que declara que ante Yahvé "toda rodilla se doblará y toda lengua confesará”, es aplicado al Señor Jesús. Ahora, ante el Nombre de Jesús "toda rodilla se dobla y toda lengua confiesa" (38), lo que implica que toda

(36) "That Phil. 2, 6-11 is a pre-Pauline hymn is widely accepted", J.D.G. Dunn, Christology in the Making, p. 114, p. 310 nn. 62 y 64 (la bibliografía es abundante). Su forma es hímnica, su contenido se presenta como conocido y va más allá de las necesidades del contexto, y, sobre todo, hay una concentración de hapaxlegómena: este breve texto contiene 5 palabras que no solo aquí

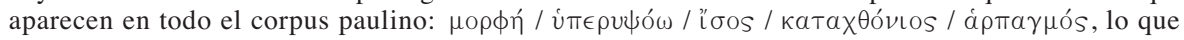
indica que la redacción no es de Pablo.

(37) Llama la atención que en un documento tan primitivo aparezca no solo el esquema de la cristología de la exaltación, sino que ya incluya la preexistencia, ofreciendo así una cristología que puede ser llamada en tres actos: preexistencia $\rightarrow$ humillación $\rightarrow$ exaltación.

(38) Is 45, 22: "Porque yo soy Dios, no existe ningún otro ${ }^{23}$. Yo juro por mi nombre; de mi boca sale palabra verdadera y no será vana: Ante mí se doblará toda rodilla y toda lengua confesará ${ }^{24}$ diciendo: ¡Solo en Yahvé hay victoria y fuerza!”. En el texto griego de Is 45, 23 y Flp 2, 11,

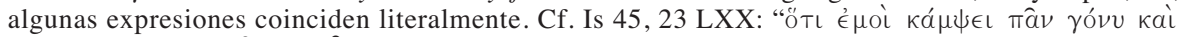

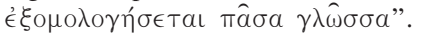


la creación adora a Jesús (39). Impresiona comprobar que en la primera década del cristianismo o, a lo sumo, en la segunda, la joven comunidad haya cantado este himno que proclama la preexistencia de Jesús exaltado y lo asocia a Dios al punto de aplicarle Is 45, 23, uno de los textos clásicos que afirman el monoteísmo, y de otorgarle el título de Kúpıos, que la versión griega del Antiguo Testamento aplicaba a Yahvé, el único Dios de Israel.

Para nuestro propósito, lo más importante es destacar la relevancia universal del Señor: "Al nombre de Jesús toda rodilla se doble en los cielos, en la tierra y en los abismos, y toda lengua confiese...”. Nada queda, entonces, exento del influjo del Señor Jesús (40). Pues se trata de un culto de todo el cosmos, no solo de la comunidad cristiana o de aquellos que lo reconocen como Señor (41).

"El universo entero saluda su triunfo y confiesa su dominio. Es impactante que sea el nombre 'Jesús' el que es utilizado" (42). El uso del nombre "Jesús” y la referencia a la muerte son una clara alusión al encarnado, que mantiene el vínculo con la revelación histórica. Aquí se aprecia la diferencia entre el kerigma cristiano y el mito (43). La antigua promesa proclamada en Isaías es ahora una realidad, en Jesús exaltado, y todo el cosmos está al servicio de la Gloria del Padre por medio del señorío de Jesús.

En síntesis, el antiguo cántico proclama el significado universal de la obra del Señor Jesús: nada queda ajeno a su influjo. Y el Señor exaltado, cuya obra tiene consecuencias universales, se identifica con Jesús, aquel que padeció la muerte, y la muerte de cruz. A pocos años de la Pascua, la comunidad canta la repercusión universal de la obra histórica de Jesús de Nazaret.

\section{b. Fórmula tradicional de fe de 1 Corintios 8,6}

En la discusión acerca de la legitimidad de comer carne inmolada a los ídolos, Pablo argumenta con una fórmula prepaulina. "Este versículo es ampliamente considerado una citación hecha por Pablo y, así, muy posiblemente la afirmación más antigua de la creencia en la preexistencia de Cristo" (44).

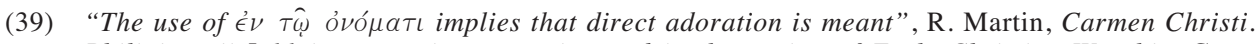
Philipians ii.5-11 in recent interpretation and in the setting of Early Christian Worship. Cambridge 1967 , p. 250.

(40) Cf. J.G. Gibbs, Creation and Redemption, p. 75.

(41) Esta es una insistencia de la obra clásica de E. Lohmeyer, Kyrios Jesus. Eine Untersuchung zu Phil. 2, 5-11, Heidelberg 1928, citado en E. Käsemann, Ensayos exegéticos, Salamanca 1978, p. 109. Cf. R. Martin, Carmen Christi. Philipians ii.5-11 in recent interpretation, pp. 252-253.

(42) R. Martin, Carmen Christi. Philipians ii.5-11 in recent interpretation, p. 253.

(43) Ver la discusión en E. Käsemann, Ensayos exegéticos, Salamanca 1978, pp. 114-115.

(44) J.D.G. Dunn, Christology in the Making, p. 179. Cf. A. Denaux, Theology and Christology in 1 Cor 8, 4-6. A Contextual-Redactional Reading, en R. Biringer (Ed.), The Corinthian Correspondence, Leuven 1996, pp. 603-606; J.G. Gibbs, Creation and Redemption. A Study in Pauline Theology, Leiden 1971, pp. 59-73; H. Conzelmann, 1 Corinthians, Philadelphia 1974, p. 144; J. Murphy-O'Connor, I Cor., VIII, 6: Cosmology or Soteriology?, RB 85 (1978), pp. 254-255; M. Hengel, El Hijo de Dios, Salamanca 1978, p. 29. La simetría de los miembros, el contenido que va más allá de lo exigido por el contexto, la presencia de una fórmula que se repite en otros lugares y la presentación de una doctrina sumamente relevante sin que se perciba la necesidad de justificarla, son algunos de los motivos que inducen a los estudiosos a reconocer como prepaulino el material contenido en la fórmula. Si Pablo argumenta con 1Co 8, 6, que contiene la afirmación 
${ }^{5}$ Pues aun cuando existan los llamados dioses, bien en el cielo bien en la tierra, en modo que hay muchos dioses y muchos señores...

${ }^{6}$ pero para nosotros [hay] un solo Dios, el Padre, del cual [proceden] todas las cosas y nosotros para Él; y un solo Señor, Jesús Cristo, por medio del cual [son] todas las cosas y nosotros por medio de él.

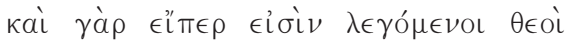

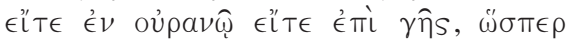

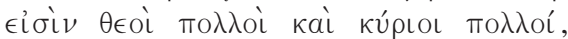

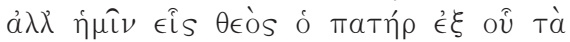

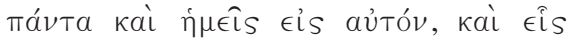

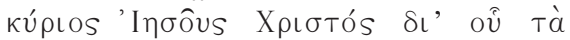

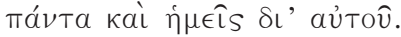

En polémica con el politeísmo pagano, el texto desarrolla la antítesis entre los llamados dioses y el único Dios verdadero, y afirma con fuerza el monoteísmo (45). Tal como en los grandes textos monoteístas del Déutero Isaías, la unicidad de Dios se manifiesta en que es Creador y Salvador de todo (cf. Is 45, 18; 51, 9-10) (46). Lo admirable es que en el contexto de una profesión de fe monoteísta, la fórmula exprese la convicción de que el Señor Jesús comparte las funciones exclusivas de Dios: su unicidad, y su universal función creadora y salvadora. En este sentido, 1Co 8, 6 es una cristianización del Shemá.

La expresión "por quien [son] todas las cosas" declara la participación del

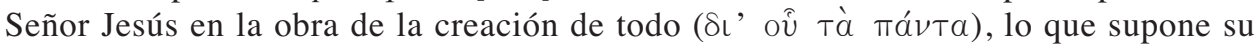
preexistencia. Y la frase "por el cual somos nosotros" atestigua la mediación del Señor Jesús en la obra de la salvación. Nada queda fuera del influjo del Señor Jesús: todo ha llegado a la existencia por medio de Él y todo alcanzará su plenitud por medio de Él.

La oposición entre los muchos [supuestos] señores y el único [verdadero] Señor, y su participación en la obra de la creación destacan la relevancia universal del Señor Jesús. Pues, "el señorío de Jesús no está limitado solo a aquellos que lo reconocen, puesto que su señorío sobre todas las cosas se ejercía por su mediación en la obra de la creación desde antes que él llegara a ser, o fuera hecho, el Mediador en la obra de la redención” (47). Así, tal como el himno de Filipenses, el señorío de Jesús alcanza también a los que no lo reconocen como Señor, pues toda la realidad proviene por medio de Él.

¿Qué relación hay entre soteriología y cosmología? Algún autor ha negado el carácter cosmológico de la fórmula, afirmando solo su significado soteriológico (48). Es cierto que la preocupación principal de Pablo es la soteriología, pero esta constatación lejos de obligar a optar, impulsa a considerar el significado cosmológico como una exigencia de la soteriología. "Pablo está usando aquí un lenguaje

de la preexistencia y de la función cosmológica del Señor Jesús, sin justificarlo, es porque considera que su contenido es conocido y aceptado por todos, es decir, su contenido es ya tradicional. Menos convencido G.D. Fee, Primera epístola a los Corintios, Buenos Aires 1994, pp. 424-425.

(45) Los 'dioses rivales' solo son $\lambda \in \gamma o ́ \mu \epsilon \nu o r ~ \theta \in o$, es decir, llamados dioses, pero no son más que 'supuestos' dioses, cf. A. Denaux, Theology and Christology in 1 Cor 8, 4-6, p. 600.

(46) Cf. A. Lemaire, Naissance du Monothéisme. Point de vue d'un historien, Bayard, Paris 2003, pp. 129-134; A. Denaux, Theology and Christology in 1 Cor 8, 4-6, pp. 601-603.

(47) J.G. Gibbs, Creation and Redemption. A Study in Pauline Theology, p. 63

(48) Cf. J. Murphy-O'Connor, I Cor., VIII, 6: Cosmology or Soteriology?, RB 85 (1978), pp. 254-255. 
que es al mismo tiempo protológico y escatológico, cosmológico y soteriológico, aún si el segundo aspecto domina" (49). La disyuntiva entre lo soteriológico y lo cósmico es falsa (50). Al contrario, la unidad entre salvación y creación, propia de la revelación bíblica, refuerza la idea que el significado soteriológico de la fórmula, lejos de excluir su sentido cosmológico, lo reclama: "En virtud de la dignidad de la revelación que tuvo lugar por medio de Cristo, el plenipotenciario absoluto de Dios debe ser, al mismo tiempo, el 'plenipotenciario' protológico. En circunstancias que las palabras y acciones de Dios al final y al principio de los tiempos forman una unidad en virtud de la verdad de Dios" (51). La preocupación soteriológica es, entonces, el punto de arranque para la afirmación cosmológica: el Mediador universal de la salvación, debe ser el Mediador universal de la obra de la creación (52).

Tal como en la profesión de 1Tim 2, 5 y en el cántico de Filipenses, el nombre "Jesús" hace referencia a la existencia histórica del Mediador, es decir, a Jesús de Nazaret, y no a un mítico Urmensch.

\section{c. La pretensión de universalidad implícita en el martirio de Esteban (53)}

Otra 'ventana' que nos permite conocer las convicciones cristológicas de la primerísima comunidad cristiana es el martirio de Esteban. Si bien Hechos debió haber sido redactado en torno a los años 80 , con métodos de la filología histórica, es posible reconocer elementos que son anteriores a su redacción final y que, por tanto, pertenecen a los primeros años del cristianismo (54).

El martirio de Esteban y la sucesiva persecución a la Iglesia, datado en los años 32/33, que tiene como consecuencia el inicio de la misión a los gentiles, son acontecimientos que nos entregan interesantes luces para conmprender los inicios de la cristología (55). El hecho del martirio muestra que ya en esos años la joven

(49) A. Denaux, Theology and Christology in 1 Cor 8, 4-6, p. 602. En la nota 23 del artículo Denaux ofrece una amplia lista de autores que reconocen este doble carácter de la fórmula.

(50) "The choice between either ethic-centered theology or cosmic-centered theology is a false choice”, J.G. Gibbs, Creation and Redemption. A Study in Pauline Theology, p. 58.

(51) M. Hengel, Hymns and Christology, en M. Hengel, Between Jesus and Paul. Studies in the Earliest History of Christianity. Fortress Press 1983, p. 95 (original alemán). Cf. además, M. Hengel, El Hijo de Dios, pp. 93-106.

(52) Cf. A. Denaux, Theology and Christology in 1 Cor 8, 4-6, p. 602: "In Paul's thinking the [soteriological] affirmation was the starting point from which he arrived at the more bold statement about Jesus' role in creation".

(53) Cf. M. Hengel, Christology and New Testament Chronology, pp. 30-47; M. Hengel, The Origins of the Christian Mission, pp. 48-64, publicados en inglés en M. Hengel, Between Jesus and Paul.

(54) Hechos no ofrecen una historia ideal de la comunidad cristiana, al contrario, refleja los conflictos; lo que otorga al relato una razonable fiabilidad histórica, precisamente porque contiene datos incómodos. Un problema diverso, sobre el que difieren las opiniones de los estudiosos, es el juicio global sobre la historicidad de los Hechos. Aquí solo nos interesa afirmar que mediante criterios filológicos es posible distinguir algunos datos históricamente confiables de Hechos de los Apóstoles. Cf. J.A. Fitzmyer, Los Hechos de los Apóstoles, Salamanca 2003, vol. I, pp. 186-191.

(55) Sobre la cronología, cf. J. Dunn (Ed.), The Cambridge Companion to St. Paul, Cambridge University Press, 2003, p. XX; M. Hengel, Christology and New Testament Chronology, p. 42. 
comunidad tenía convicciones tan sólidas como para provocar un severo conflicto con el judaísmo (56). ¿Cuál es el contenido de la controversia?

Según Hech 6, 8-10, algunos judíos de las sinagogas de lengua griega consideraron inadmisible la predicación de Esteban, otro judío de lengua griega. Las razones de la controversia se aclaran al estudiar las acusaciones contra Esteban (Hech 6, 11-14). Lo que ofendía a los judíos era la actitud de los cristianos ante la Ley. "Pero ¿en qué pecaban estos contra ella? A esto se responde que, al poner a Jesús en el centro de la religión, arrebataban con este mismo hecho a la Torá el lugar que esta ocupaba en el judaísmo” (57). Así, al menos algunos cristianos, en los años 32/33, contra la religión tradicional, afirmaban que el punto de referencia definitivo para la salvación ya no era la Ley y el Templo, sino Jesús (58).

La muerte del primer mártir tiene como consecuencias la persecución, la huida de los judeocristianos helenistas de Jerusalén y el sucesivo inicio de la misión a los paganos realizada por los que escapaban de la persecución (cf. Hech 8, 1-5; 11, 1920) (59). A partir del año 33, ya hay judeocristianos que realizan una misión dirigida a los paganos. ¿Qué convicciones supone esta novedosa misión a los gentiles?, ¿cómo se explica este explosivo impulso misionero que se abre a los paganos? (60). Este explosivo impulso misionero debió basarse en un también explosivo desarrollo de la cristología (61).

La misión universal supone la convicción de la relevancia salvífica universal del Señor Jesús, es decir, que la salvación de toda la humanidad depende de Jesús. Esto tiene consecuencias revolucionarias: Ya no es necesaria la observancia de la Ley para la salvación porque Jesús ha tomado el lugar de la Ley y del Templo.

(56) Pablo, describiendo su anterior conducta en el judaísmo, se define: "en cuanto al celo, perseguidor de la Iglesia” (Flp 3, 6), es decir, menciona las persecuciones que había realizado como señal de la seriedad con que tomaba el judaísmo, lo que muestra la incompatibilidad entre el judaísmo y las creencias de la nueva comunidad de seguidores de Jesús. Cf. J. Murphy-O’Connor, Paul. A Critical Life, Oxford University Press, 1997, p. 67.

(57) S. Légasse, Pablo Apóstol, p. 69. "Es difícil para el hombre moderno occidental imaginar el sentimiento de santidad que inspiraba el Templo... El Templo era santo no solo porque el Dios santo allí era adorado, sino porque Él estaba ahí”, E.P. Sanders, Il Giudaismo. Fede e prassi, pp. 95-96.

(58) "El tradicional evento salvífico del éxodo y la revelación del Sinaí estaban siendo devaluados a la luz del tiempo de salvación que estaba amaneciendo con Jesús. En Jesús se expresa algo no solo mayor que Jonás y Salomón, sino también mayor que Moisés”, M. Hengel, Between Jesus and Paul. The 'Hellenists', the 'Seven' and Stephen (Acts 6.1-15; 7.54-83), en M. Hengel, Between Jesus and Paul, p. 23.

(59) Según el relato de Lucas, la misión a los gentiles no fue iniciada por los propios apóstoles, sino por judíos de habla griega (por outsiders, es decir, no los apóstoles), que huyendo de la persecución, desatada por el martirio de Esteban, comenzaron la actividad misionera en Samaria, Fenicia, Chipre y Antioquía. Esta descripción está muy lejos de ser una historia ideal, pues se trata de datos incómodos. Cf. M. Hengel, The Origins of the Christian Mission, p. 55.

(60) Solo una convicción cristológica muy fuerte es capaz de sustentar esta novedad que rompe con los condicionamientos culturales y religiosos que impedían la misión abierta a los gentiles. Cf. L.W. Hurtado, Early Jewish Opposition to Jesus-Devotion, en L.W. Hurtado, How on Earth Did Jesus Become a God? Historical Questions about Earliest Devotion to Jesus, Eerdmans, Michigan / Cambridge 2005, pp. 168-178.

(61) "El entusiasmo misionero-escatológico necesitó un mensaje definido en modo relativamente claro para servir de base a las iglesias que estaban siendo fundadas”, M. Hengel, 'Sit at My Right Hand'. The Enthronement of Christ at the Right Hand of God and Psalm 110, 1, en M. Hengel, Studies in Early Christology, T\&T Clark, 2004, p. 219. 
Impresiona que tan tempranamente, cuando la Iglesia no tenía ninguna expectativa humana de llegar a todos los pueblos, se encuentre ya, al menos implícita, la idea de que Jesús tiene significado salvífico universal.

Finalmente, ¿dónde tienen sus raíces estas ideas?, ¿qué impulsa a los cristianos a declarar a Jesús de Nazaret superior al Templo y a la Ley, mediador universal de la salvación y ministro de la creación? El origen de estas afirmaciones, tan discontinuas con la piedad israelita tradicional, hay que buscarlas en la actividad terrena de Jesús mismo (62). Se trata de "inferir causas a partir de los resultados", puesto que, "por el humo se sabe dónde está el fuego" (63).

\section{5. ¿ ¿Pretensión universal en Jesús de Nazaret?}

Este recorrido retrospectivo nos ha llevado hasta Jesús mismo. De más está indicar que esta tarea exige gran cuidado crítico, pero también vale la pena recordar que en las últimas décadas ha crecido confianza en que es posible acceder históricamente a Jesús. E.P. Sanders, uno de los más ilustres representantes de la Third Quest, en su libro Jesús y el judaísmo, afirma: "El punto de vista que predomina hoy es que podemos conocer con certeza lo que Jesús pretendía realizar, que sabemos bastante sobre su enseñanza y que ambos aspectos cobran sentido en el marco del judaísmo del siglo I" (64).

Últimamente, con especial participación de B. Witherington (65), se ha desarrollado la así llamada “cristología de Jesús”, es decir, el estudio crítico, basado en los criterios de autenticidad histórica (66), que intenta saber "cómo concibió Jesús su relación con Dios y su puesto en el plan divino” (67). Para el presente propósito, la tarea consiste en identificar y seleccionar de entre los datos que arroja la "cristología de Jesús” aquellos elementos propios del Jesús prepascual que fundamentan la convicción de que Jesucristo tiene relevancia salvífica universal, única y definitiva. No se pretende dar una visión completa de la cristología de Jesús, sino presentar los datos que son útiles para aclarar el fundamento de la pretensión de unicidad y universalidad de la primera cristología postpascual.

a. La cercanía de Jesús con los pecadores y el perdón ofrecido a ellos son datos históricamente sólidos (68). En estos contextos, Jesús se presenta como quien

(62) “La critica de los helenistas a la Torá y al Templo, debió haber sido la continuación de principios que estaban en el anuncio de Jesús, que se remontaban a uno o tres años antes, y estaban presentes en la memoria más inmediata”, M. Hengel, Il Paolo precristiano, Brescia 1992, p. 188.

(63) Se trata del método de J. Klausner y J. Knox, cf. E.P. Sanders, Jesús y el judaísmo, pp. 20.33.

(64) E.P. Sanders, Jesús y el judaísmo, Trotta 2004, p. 18.

(65) B. Witherington, The Christology of Jesus, Forteress Press 1990.

(66) Cf. J.P. Meier, Un judío marginal, vol. I, pp. 183-209; R. Latourelle, A Jesús el Cristo por los Evangelios, Salamanca 1986, pp. 202-226; J. Schlosser, Jesús, el Profeta de Galilea, Salamanca 2005, pp. 67-76; A. Vargas Machuca, El Jesús histórico. Un recorrido por la investigación moderna, Comillas Madrid 2004; A. Cadavid, La investigación sobre la vida de Jesús, Telogía y Vida, XLIII (2002), pp. 512-540.

(67) R.E. Brown, Introducción a la cristología del Nuevo Testamento, Salamanca 2001, p. 31. Cf. R. Penna, I ritratti originali di Gesù il Cristo. Inizi e sviluppi della cristologia neotestamentaria, Roma 1996, vol. I , pp. 33-171.

(68) Las duras palabras contra Jesús provocadas por estas actitudes son testimonio de su historicidad: “ ¡Ha blasfemado!” (Mc 2, 7; cf. Lc 7, 49); “Ahí tenéis un comilón y un borracho, amigo de 
se concibe a sí mismo como alguien con autoridad para perdonar pecados, lo que es una prerrogativa exclusiva de Dios. La comunión de mesa de Jesús con "publicanos y pecadores" (Mc 2, 13-17; Mt 11, 19) es un signo profético del perdón ofrecido gratuitamente por Él. Según Meier, “A los ojos de los judios rigoristas, la convivialidad de Jesús con los ritual o moralmente impuros le comunicaba impureza. Pero Jesús veía el asunto desde una perspectiva opuesta: él comunicaba salvación a los marginados religiosos” (69). Jesús se concibe a sí mismo como el profeta definitivo, con autoridad, el que actúa en lugar de Dios, y convoca y sirve el banquete escatológico al que están invitados "los que no pueden pagar" (Is 55, 1, cf. 25, 6). "El que Jesús actuara como si estuviera haciendo las veces de Dios era implícitamente un acto cristológico. El acto se hace explícito con la pregunta de los adversarios: ‘QQuién puede perdonar pecados sino Dios solo?"” (70).

b. La actitud de Jesús frente a la Ley no es homogénea: a veces la cumple, a veces no la observa, a veces la vuelve más exigente. Este comportamiento, que está fuera de la sospecha de los críticos (71), muestra que Jesús se concibe a sí mismo como alguien que tiene soberanía sobre la Ley. Corrige la Ley en primera persona: "Yo os digo..." (72). Para los contemporáneos de Jesús, la Ley era la expresión máxima de la revelación divina, y vemos que Jesús se sitúa por sobre la Ley y como referente último en lo que se refiere a la relación con Dios.

c. Más difícil es fundamentar, en la actividad terrena del Maestro de Galilea tal como hoy se puede reconstruir, el carácter universal del alcance de la obra de Jesús. Hay textos muy problemáticos en lo que se referiere a la relación de Jesús con los paganos (73), mientras otros textos declaran las proporciones universales del ministerio de Jesús, como Mt 11, 27 (que veremos más abajo), pero algunos de ellos pueden estar influenciados por la situación eclesial posterior a la Pascua (74). Los estudios muestran que el camino del examen de determinados versículos no se muestra fecundo. Aquí habría que argumentar de otra manera: el modo más razonable de comprender por qué los primeros cristianos, que eran de origen judío, en discontinuidad con el judaísmo, emprendieron una misión de alcance universal es suponer que Jesús mismo debió

publicanos y pecadores" (Q Lc 7, 34; Mt 11, 19). No es razonable que la Iglesia haya inventado una acusación tan fuerte como la de blasfemia. Al contrario, la comunidad tiende a suavizar las acusaciones hechas contra Jesús.

(69) J.P. Meier, Un judío marginal, vol. II/1, p. 369. Por pecadores hay que comprender no solo los moralmente impuros, sino también los ritualmente impuros, es decir, aquellos que por su oficio, situación social, etc., estaban excluidos de la comunión con el culto y con pueblo de la Alianza.

(70) E. Schweitzer, Jesús, parábola de Dios, pp. 71-72.

(71) Cf. R. Fabris, Jesús de Nazaret. Historia e interpretación, pp. 118-123. Las múltiples acusaciones contra Jesús de ir contra la Ley confirman la historicidad de estas actitudes descritas por los evangelios sinópticos.

(72) En el sermón de la montaña de Mt 5, muchas afirmaciones de Jesús corrigen afirmaciones de la Ley de Moisés. Cf. Ex 20, 13; Ex 20, 14; Ex 20, 7; Nm 30, 3; Dt 23, 22; Ex 21, 24; Lv 19, 18.

(73) Así, por ejemplo, Mt 8, 11-12; 15, 24; 10, 5; 25, 32; 28, 19-20; Mc 7, 27; 13, 10 (curiosamente Mc 7, 27 tiene una tendencia más universalista que su paralelo en Mt 10, 26). Cf. J. Gnilka, Teología del Nuevo Testamento, Trotta 1998, pp. 188-189.

(74) Cf. E.P. Sanders, Jesús y el judaísmo, Editorial Trotta, Madrid 2004, pp. 311-324. 
haber dado señales en ese sentido, de otro modo la misión no se explica (criterio de la explicación necesaria) (75). "La abrumadora impresión es que Jesús comenzó un movimiento que llegó a ver su misión a los paganos como una prolongación lógica de sí mismo” (76).

d. Es históricamente seguro que Jesús entró en conflicto con el Templo (77). Para los israelitas, el Templo único significaba la unidad de Dios y la unidad del pueblo; era la morada de Dios y el lugar donde se realizaba la remisión de los pecados por medio del culto sacrificial. El hecho es claro, pero no su significado: ¿Qué intención hay detrás del gesto de Jesús en el Templo? Se trata de un gesto simbólico, como las acciones de los profetas (78), y simboliza la destrucción del Templo, que a su vez apunta la promesa de su restauración (79). Así concuerda la acción de Jesús con sus palabras (80). Jesús asume, entonces, una función propia de Dios y expresa que han llegado los últimos tiempos, es decir, la destrucción del orden antiguo y el inicio del definitivo. Este gesto "indirectamente comportaba la equiparación de Jesús con Dios” (81). "Lo que [Jesús] habría querido decir es que actuaba como agente de Dios en el contexto del eschaton” (82). Jesús se concebía a sí mismo como el que, de modo definitivo e incomparable a los demás enviados, actúa en nombre de Dios.

e. El modo como Jesús llama a dejarlo todo y seguirlo a él (no a la Ley o a Dios, como los maestros) manifiesta de modo particular la conciencia de su propia identidad (83).

(75) Cabe recordar que, según el testimonio de Gálatas, el punto de conflicto no es la legitimidad de la misión a los gentiles, sino la obligatoriedad de la Ley de Moisés. lo mismo se aprecia en Hechos: "Bajaron algunos de Judea que enseñaban a los hermanos: 'Si no os circuncidáis conforme a la costumbre mosaica, no podéis salvaros' [...]. algunos de la secta de los fariseos, que habían abrazado la fe, se levantaron para decir que era necesario circuncidar a los gentiles y mandarles guardar la Ley de Moisés" (Hech 15, 1.5). Los "fariseocristianos" no están en contra de la misión a los paganos sino que afirman que los convertidos del paganismo deben se circuncidados y observar la Ley.

(76) E.P. Sanders, Jesús y el judaísmo, pp. 323-324.

(77) “Está fuera de duda que se produjo realmente”, E.P. Sanders, Jesús y el judaísmo, p. 100 (cf. todo el capítulo, Jesús y el Templo, pp. 99-123). Los cuatro evangelios presentan a Jesús prediciendo la destrucción del Templo, realizando su "purificación" y siendo acusado de haber pronunciado la amenaza de destruir y reconstruir el Templo, palabras que se repiten en el juicio contra Esteban (Hech 7). Estos datos muestran con claridad que el conflicto en torno al Templo ciertamente es de carácter histórico.

(78) E.P. Sanders, uno de los grandes estudiosos del judaísmo y cristianismo antiguos, ha insistido en que el gesto realizado por Jesús en el Templo no se reduce a una oposición al carácter material de los sacrificios o a los abusos de los sacerdotes o del comercio, tampoco es solo un signo de indignación ante la exclusión de los gentiles y mucho menos es un intento fallido de iniciar una revuelta. Cf. E.P. Sanders, Jesús y el judaísmo, pp. 101-116.

(79) Tanto en algunos textos proféticos como en otros textos intertestamentarios se anuncia una renovación del Templo operada al final de los tiempos por Dios mismo. En uno de los rollos de Qumrán se lee: "Santificaré mi Templo con mi gloria, porque haré habitar en él mi gloria hasta el día de la bendición, cuando yo mismo cree mi Templo, estableciéndolo para mí por siempre” (11QT 29, 810). Esta esperanza no coincide con el simple deseo de un Templo construido con mayor esplendor, es una esperanza que mira a una renovación radical del culto, cuyo autor será Dios mismo.

(80) Cf. Mc 13, 1-2; 14, 57-58; 15, 29; Mt 26, 60-61; 27, 40; Jn 2, 18-22; Hech 6, 14.

(81) R. Penna, Il DNA del cristianesimo, p. 79.

(82) E.P. Sanders, Jesús y el judaísmo, p. 121.

(83) Cf. M. Hengel, Seguimiento y carisma. La radicalidad de la llamada de Jesús. Santander 1981; R. Penna, I ritratti originali di Gesù el Cristo, vol. I, pp. 45-57; B. Witherington, The Christology of Jesus, Fortress Press 1990, pp. 118-143. 
Mc 8, ${ }^{35}$ (= Lc 9, 24, Mt 16, 25): "Porque quien quiera salvar su vida, la perderá; pero quien pierda su vida por mí y por el Evangelio, la salvará”.

$Q$ (= Lc 14, 26-27, Mt 10,37-38): "[El que] no odia a su padre y a su madre no puede ser discípulo mío, y [el que] no odia a su hijo y a su hija no puede ser discípulo mío. ${ }^{27}$ [...] El que no toma su cruz y viene detrás de mí, no puede ser discípulo mío".

$Q$ (= Lc 9, 59-60, Mt 8, 21-22): "Otro le dijo: Señor, Déjame que vaya primero a enterrar a mi padre. Y le dijo: Sígueme, y deja a los muertos enterrar a sus propios muertos" (84).

La rudeza y radicalidad del lenguaje desaconseja pensar que estas palabras tengan su origen en la tradición eclesial (son demasiado incómodas y disfuncionales). Tampoco pueden provenir del judaísmo, que, en su fibra cordial, destaca el amor a los padres y la obligación de enterrar a los muertos (85). Además, dos de estos textos que provienen de $Q$, que contiene dichos de Jesús que pertenecen de los estratos más antiguos de la tradición evangélica (86). Este radicalismo y la centralidad de Jesús son nuevos en comparación con las vocaciones proféticas. Luego, estas palabras deben provenir de Jesús mismo.

¿Qué relación establece Jesús entre la aceptación o rechazo a su llamada y la vida del hombre? Seguir o rechazar a Jesús tiene consecuencias definitivas. Jesús manifiesta que la obediencia a su llamada está por sobre los lazos humana y religiosamente más altos, los de la familia. Los muertos que entierran muertos son aquellos que, por no seguir a Jesús, pierden su vida, es decir, son muertos. La centralidad de Jesús en la historia de la salvación aparece de modo casi chocante: Ganar o arruinar la vida depende de aceptar o rechazar a Jesús. En cierto sentido, ante Jesús, se juega el juicio final (87). "Jesús ha venido a traer el juicio decisivo de Dios sobre la tierra [...] ahora es la hora de la decisión y el modo como uno decide acerca de la obra y de la persona de Jesús y su proclamación acerca del dominio de Dios afectará nuestras relaciones personales y nuestra situación final ante Dios” (88). El juicio definitivo, entonces, se realiza ante Jesús.

(84) Cf. M. Hengel, Seguimiento y carisma. pp. 13-30; 99-105 y 126-129.

(85) Es propio de la ley, la moral y la fibra cordial de la religiosidad judías la preocupación por los padres y en especial por enterrar a los padres, por ello, Mt 8, 22 es el texto en que Jesús se opone de modo más drástico a la Ley. El libro de Tobías es testigo de la importancia que el judaísmo otorga a la obligación de enterrar a los muertos, esta obligación se extrema en el caso del padre que incluso dispensa de las obligaciones religiosas más sagradas.

(86) Cf. J.D.G. Dunn, Redescubrir a Jesús de Nazaret, pp. 32-34. Muchos estudiosos sitúan la composición de $Q$ en la década de los 50-60, pero para ello deben hipotizar una comunidad galilea que no conocía o que no se interesó por la muerte y resurrección de Jesús, lo que resulta muy poco plausible, por ello un importante grupo de estudiosos prefieren situar la configuración global de $Q$ en Galilea, aún antes de la Pascua, cf. J.G. Dunn, Jesus Rememberd, Cambridge 2003, p. 160; D.C. Allison, The Jesus Tradition in Q, Harrisburg: Trinity 1997, p. 60-62; D.R. Catchpole, The Quest for Q, Edinburgh: Clark 1993, p. 188; M. Hengel, Jesus as Messianic Teacher of Wisdom and the Beginnings of Christology, en M. Hengel, Studies in Early Christology, T\&T Clark, 2004, pp. 76.

(87) Esta idea aparece en otro texto que seguramente proviene de los labios de Jesús: "He venido a arrojar fuego sobre la tierra y ¡cuánto desearía que ya estuviera ardiendo!” (Lc 12, 49, cf. Mt $10,32-40)$.

(88) B. Witherington, The Christology of Jesus, p. 122. 
f. El carácter único de Jesús se expresa en su relación con Dios, su Padre (89). La paternidad de Dios no es un concepto muy desarrollado en el Antiguo Testamento (90). En cambio, el examen de las tradiciones evangélicas revela que hay algo nuevo y único en la relación de Jesús con Dios: Cuando Jesús se

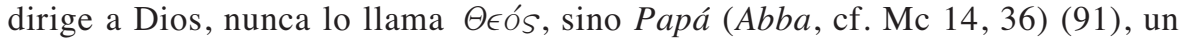
apelativo casi escandaloso para la oración judía por ser demasiado familiar para referirlo a Dios.

Estudiamos tres textos que podemos considerar como los más significativos. El primero proviene de Marcos:

"Mas de aquel día y hora, nadie sabe nada, ni los ángeles en el cielo, ni el Hijo, sino solo el Padre" (Mc 13, 32).

La ignorancia confesada por el Hijo es señal de la autenticidad de este logion, en él, Jesús se autodenomina "el Hijo", en absoluto y con artículo, y se autositúa como superior a los ángeles, lo que destaca el carácter único de su relación con el Padre. "Pertenece a la autoconciencia de Jesús haberse sabido, afirmado y reconocido como el Hijo" (92).

En este mismo sentido se puede citar la parábola de los viñadores homicidas, considerado parte del mensaje histórico de Jesús:

“... y también envió a muchos otros, hiriendo a unos, matando a otros. Todavía le

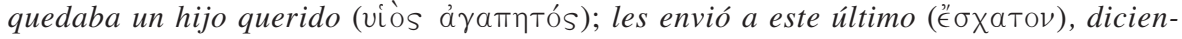
do: 'Respetarán a mi hijo' (o 'viós rov)" (Mc 12, 5-6; Ev. de Tomás, 65).

En la parábola, sin duda tiene una intención cristológica: el dueño de la viña simboliza a Dios, y Jesús compara su propia misión con la del hijo amado de Dios (93), todos los demás son siervos ( $\delta \circ \hat{\lambda} \lambda o \iota)$, afirma que su ministerio representa el clímax escatológico, es decir, la etapa definitiva y final ( y manifiesta que su propia filiación respecto de Dios posee un carácter único y definitivo (94).

El tercer texto, el más significativo, procede del documento $Q$ :

(89) La obra fundamental sobre este tema es la de J. Jeremias, El mensaje central del Nuevo Testamento, Salamanca 1966. Posteriormente ha sido rebatida y completada, pero la tesis central se mantiene. Cf. J. Schlosser, El Dios de Jesús. Estudio exegético, Sígueme, Salamanca 1995; J.D.G. Dunn, Christology in the Making, pp. 22-33.

(90) Dios se revela en unos pocos textos como Padre del pueblo o del rey, menos frecuentemente, como Padre del individuo (en textos más tardíos), y en ambiente más helenista, se destaca la paternidad universal en estrecha dependencia con la teología de la creación (cf. Is 1, 2-3; Is 63, 7 64, 11; Os 11, 1-4). La cercanía de Dios se completa con los rasgos maternales que el AT le atribuye a Dios (cf. Dt 32, 6.18; Os 11, 1-9; Is 49, 15; 66, 13).

(91) Jesús nombra a Dios como como Padre 4 veces en Mc y 5 veces en $Q$ (se han dejado fuera las menciones que deben provenir de los redactores). Cf. Lc 6, 36/Mt 5, 48; Lc 10, 21-22/Mt 11, 25 27; Lc 11, 2/Mt 6, 9; Lc 11, 13/Mt 7, 11; Lc 12, 30/Mt 6, 32; Mc 11, 25; Mc 13, 32; Mc 14, 36.

(92) Cf. O. González de Cardedal, Fundamentos de cristología, vol. II, Madrid 2006, p. 102.

(93) J.D.G. Dunn, Jesus Rememberd, p. 722.

(94) "We may conclude that Jesus sensed an eschatological uniqueness in his relationship with God", J.D.G. Dunn, Christology in the Making, p. 28 (destacados del autor). 
"Todo me ha sido entregado por mi Padre, y nadie conoce al Hijo sino el Padre, y nadie conoce al Padre sino el Hijo, y aquel a quien el Hijo se lo quiera revelar" ( $Q$ 10, 22 [Lc 10, 22/Mt 11, 27]).

Es tan densa la revelación de estas palabras de Jesús, que han sido consideradas "un meteorito caído del cielo de Juan" (95), a lo que O. Cullmann replica: "No tenemos ninguna razón para declarar inauténtico el logion de Mt 11, 27 simplemente porque tiene un estrecho parentesco con un tema favorito del evangelio de Juan" (96). M. Hengel afirma que encontramos aquí, en el propio mensaje de Jesús, las raíces de la cristología joánica (97), y James Dunn declara que "este pasaje de $Q$ puede indicar uno de los brotes que condujo al pleno florecimiento joánico” (98).

Tal como señalan algunos importantes comentaristas, la fórmula "es sobre todo la revelación de una relación interpersonal totalmente inédita” (99); "lo que aquí se dice sobre la filiación propia de Jesús entraña algo único y radicalmente diferente" (100). "Jesús es revelador del Padre en plenitud porque le conoce con exhaustividad, lo mismo que el Padre le conoce a él. El conocimiento que Jesús posee de Dios como su Padre es recíproco o equivalente con el que el Padre tiene de él y por ello perfecto y exhaustivo" (101). "Solo Jesús conoce al Padre con la intimidad que lo autoriza a llamar a Dios Abba. Esto implica la pretensión de que Jesús es el mediador exclusivo del verdadero conocimiento de Dios o de la sabiduría de Dios" (102). "Este sentido de filiación debió ser crucial, incluso central, para la propia autocomprensión de Jesús y la fuente de la inmediatez de la autoridad con la que proclamó el reino de Dios” (103).

En este logion, Jesús se presenta como el Hijo único que, por tener una relación exclusiva con el Padre, es el Único por medio del cual se revela el Padre a todos los hombres (104). En síntesis, de acuerdo a este versículo, "Jesús se vio a sí

(95) K. v. Hase, Geschichte Jesu, 1876, p. 422, citado en O. Cullmann, Cristología del Nuevo Testamento, p. 369.

(96) O. Cullmann, Cristología del Nuevo Testamento, p. 370.

(97) Cf. M. Hengel, Jesus as Messianic Teacher of Wisdom and the Beginnings of Christology, pp. 88.

(98) J.D.G. Dunn, Jesus Rememberd, p. 719.

(99) F. Bovon, L'Évangile selon Saint Luc, vol. IIIb, Genève 1996, p. 75.

(100) "La intimidad que existe entre Padre e Hijo solo la conocen ellos mismos, que son los propios implicados, y aquellos a los que, por condescendencia, se lo quiera revelar el Hijo. Lo que se acentúa en esta clase de intimidad es el carácter único y exclusivo de la filiación de Jesús [...] lo que aquí se dice sobre la filiación propia de Jesús entraña algo único y radicalmente diferente”, J. Fitzmyer, El Evangelio según San Lucas. Traducción y comentario, vol. III, Madrid 1987, p. 261.

(101) O. González de Cardedal, Fundamentos de cristología, vol. II, p. 102.

(102) B. Witherington, The Christology of Jesus, pp. 227-228.

(103) J.D.G. Dunn, Jesus Rememberd, p. 724.

(104) "El conocimiento de que habla el versículo es un conocimiento de lo igual por lo igual [...] Lo mismo que en las doctrinas místicas, el conocimiento de Dios parte aquí también exclusivamente de Dios. Y como allí, el conocimiento no es un acto disociable del sujeto que conoce: el Hijo es Hijo al conocer al Padre [...] No hay en el versículo nada parecido a un camino hacia la sabiduría desde el mundo sensible hasta la cima de lo espiritual -como se da en Filón, sobre todo-; se trata del camino unilineal desde el Padre al Hijo, y solo desde este a los humanos [...] Se trata exclusivamente de Cristo y no de una relación mística fundamental para todo ser humano. En todo caso, el v. 27 no pone a los fieles en una relación análoga con el Padre [...] De ahí que les sea revelado también, además del misterio del Padre, el misterio del Revelador, del Hijo”, U. Luz, El Evangelio según San Mateo, vol. II, Salamanca 2001, p. 288. 
mismo como el mediador único de la revelación final de Dios y, así, como el Hijo único de Dios" (105). De este modo, se vincula la única y exclusiva filiación divina de Jesús con su función única y universal de mediación entre Dios y los hombres. Este logion se abre al registro sapiencial que vincula a Jesús de Nazaret con la Sabiduría que ofrece a los hombres entrar en la intimidad de Dios (106).

\section{VISIÓN DE CONJUNTO}

\section{Origen de la cristología de pretensión universal}

¿Cómo se desarrolló el proceso por el cual Jesús, pocos años después de su muerte, fue considerado superior a la Ley y al Templo, recibió culto y se lo proclamó Hijo de Dios preexistente, ministro universal de la salvación y mediador en la creación de todo? ¿Cómo, en pocos años, el Galileo ajusticiado llegó a ser considerado merecedor de la adoración de todo el cosmos? Este ha sido llamado "el problema capital de la cristología” (107).

\section{Jesús, fundamento de la cristología eclesial de valor universal}

Las raíces de este proceso deben encontrarse en el ministerio histórico de Jesús. Tal como hemos visto, en su cercanía con los pecadores y en el perdón que les ofrece, Jesús se pone en el lugar de Dios; en la soberanía que muestra frente a la Ley, al corregirla en primera persona, y en su gesto en el Templo, Jesús se sitúa a sí mismo como el referente definitivo (escatológico) en lo que se refiere a la relación con Dios; en algunas llamadas a su seguimiento, Jesús muestra una radicalidad con que él mismo se sitúa por sobre los amores y obligaciones más nobles, afirmando que ganar o arruinar la vida depende de aceptar o rechazar su llamada: el juicio definitivo se realiza ante Jesús. Finalmente, en su relación con Dios, el punto capital y el fundamento de los demás, Jesús se autocomprende como "el Hijo", que tiene una relación filial inédita, única y exclusiva con Dios su “Abba”, y, por ello, tiene la misión única y universal de revelar al Padre.

La existencia terrena de Jesús de Nazaret comporta, entonces, una determinada autocomprensión, pues "nadie puede ser algo para los otros, si primero no es algo en sí mismo” (108). De este modo, aún antes de la Pascua está presente la realidad que solo después será manifiesta. Debemos, entonce, reconocer en el Predicador de Galilea una tal autocomprensión de ser "el Hijo" que justifique la verdad del desarrollo cristológico postpascual, y haga históricamente comprensible este desarrollo,

(105) B. Witherington, The Christology of Jesus, p. 228.

(106) Cf. Job 28, 1-27; Sir 1, 6-8; Bar 3, 15-32; Prov 8, 12; Sab 7, 25-27; 8, 3-8; 9, 4.9.11; B. Witherington, The Christology of Jesus, p. 227; U. Luz, El Evangelio según San Mateo, vol. II, p. 283; M. Hengel, Jesus as Messianic Teacher of Wisdom and the Beginnings of Christology, pp. 87-89.

(107) Cf. M. Hengel, El Hijo de Dios, Salamanca 1978, pp. 11-12, citando a M. Dibelius, Der Hauptproblem der Christologie, RGG 1, 1953.

(108) R. Penna, I ritratti originali di Gesù il Cristo, vol. I, p. 8. 
puesto que un Jesús que de ningún modo se sabe Hijo único de Dios no explica históricamente por qué la comunidad posterior lo proclamó como tal. El sentido en que Jesús experimentó su filiación divina "es de crucial importancia para toda la cristología sucesiva, puesto que sin este carácter distintivo y único todos los desarrollos de la cristología posteriores a la Pascua, por no mencionar los desarrollos de los siglos subsecuentes, estarían en riesgo de perder contacto con quien Jesús de hecho fue" (109). Se trata, entonces, de reconocer en el ministerio y en la autocomprensión del Maestro de Galilea las raíces que justifican el desarrollo cristológico posterior, realizado por una comunidad que se constituyó en torno a Jesús de Nazaret. La exégesis avanza hasta afirmar el "hecho" de la autocomprensión filial sin que pueda aclarar su “modo” (110).

Ahora bien, la autocomprensión histórica manifestada por Jesús de Nazaret conduce a una disyuntiva: ¿Jesús es la autocomunicación definitiva de Dios o es un blasfemo?, ¿quién puede perdonar pecados?, ¿quién tiene soberanía sobre la Ley y el Templo?, ¿quién puede hacer depender la vida y la muerte de la aceptación o rechazo del propio seguimiento?, ¿quién es este que trata a Dios de un modo íntimo y totalmente inédito? Con razón le preguntaban: “¿Con qué autoridad haces esto?, o ¿quién te ha dado tal autoridad para hacerlo?” (Mc 11, 28). Esta disyuntiva alcanza su cenit en la muerte: la cruel e ignominiosa crucifixión, ¿es la confirmación de que Jesús era un blasfemo que, siendo hombre, pretendía ser Dios (111), o bien, es culminación de la autodonación divina que nos manifiesta de modo inaudito de qué manera ama Dios al mundo? (cf. Jn 3, 16).

¿Cómo se responde a esta disyuntiva? Solo el Padre puede responder. Jesús, en su vida terrena, no podía de modo explícito declararse a sí mismo "Hijo de Dios", solo el Padre podía hacerlo. Y fue justo lo que el Padre hizo al resucitar a Jesús de entre los muertos (112). Es lo que afirma la antigua fórmula cristológica conservada por Pablo: Jesús el Cristo, Señor nuestro, nacido del linaje de David según la carne, ha sido constituido (=declarado) Hijo de Dios con poder, según el Espíritu, a partir de la resurrección de entre los muertos (cf. Rom 1, 3-4).

Origen de la cristología eclesial de valor universal

¿Cómo se desarrolló, entonces, la primera cristología postpascual? El Predicador de Galilea, que fue humillado hasta la muerte de cruz, fue exaltado por el Padre hasta ser establecido "a la diestra del trono de Dios" (Sal 110,1). A partir de la resurrección, cuando se culmina la revelación de la identidad del Hijo, la joven comunidad reflexiona: Aquel que hoy comparte el trono de Dios debió participar

(109) J.D.G. Dunn, Christology in the Making, p. 33.

(110) 'Schweitzer's claim that Matt. 11, 27 'may be spoken from the consciousness of pre-existence' is never more than a possibility, neither finally excluded nor positively indicated by careful exegesis”, J.D.G. Dunn, Christology in the Making, p. 29. Cf. O. Cullmann, Cristología del Nuevo Testamento, p. 371. Ha sido tarea de la cristología sistemática enfrentar este complejo y crucial tema.

(111) Jn 10, 33: “Le respondieron los judios: 'No queremos apedrearte por ninguna obra buena, sino por una blasfemia y porque tú, siendo hombre, te haces a ti mismo Dios'”.

(112) Cf. Hengel, Jesus as Messianic Teacher of Wisdom and the Beginnings of Christology, pp. 108109 . 
desde siempre de la igualdad con Dios (113). Por la resurrección, Dios mismo confirma la autocomprensión de Jesús, es decir, su pretensión de tener autoridad para perdonar pecados, de ser soberano sobre la Ley y el Templo, de afirmar que ganar o arruinar la vida depende de la aceptación o rechazo a la llamada a su seguimiento, en definitiva, su pretensión, que fundamenta las demás, de tener una relación única y exclusiva con Dios, su Abba, al punto de que nadie conoce al Padre sino el Hijo y aquellos a los que el Hijo se lo quiera revelar (cf. $Q 10,22)$. En la resurrección, Dios Padre dio la razón a Jesús: no era un blasfemo, sino su Hijo único. La pretensión de Jesús queda confirmada por la resurrección.

Pero, ¿cómo llegó a ser proclamado Señor de todo el cosmos? El significado cosmológico del Señor Jesús, que fundamenta su significado universal, posiblemente se desarrolló como una exigencia interna de la cristología de la exaltación. El rol del Señor en la creación se deduce de su actividad terrena y de su rol actual en la salvación: lo primero que se testifica es la salvación y, a partir de ella, se reflexiona acerca de la creación (114). "Este paso no fue una falsificación gnóstica y sincretística, sino la última consecuencia necesaria del pensamiento cristiano primitivo” (115).

La universalidad salvífica de Jesús, en virtud de la unidad entre salvación y creación, exige la participación del Salvador universal en la obra universal de la creación. El principio está explícitamente enunciado en la Carta de Bernabé: "He aquí que hago las cosas últimas como las primeras” (116). En la teología judía del siglo I hay una estrecha relación entre soteriología y protología. Entonces, "el problema de la 'preexistencia' surgió, necesariamente, de la vinculación entre las ideas judías sobre la historia, el tiempo y la creación, y de la certeza de una plena revelación de Dios realizada en su Mesías, Jesús de Nazaret” (117). De este modo, la función creadora del Señor Jesús no surge de la curiosidad cosmológica propia del espíritu griego, sino como una exigencia interna de la teología cristiana que, en un contexto palestinense, reflexiona la novedad cristiana. No es necesario recurrir a la hipótesis de la helenización del cristianismo (entendida como corrupción), pues "ya había una cristología de Cristo Mediador de la creación en el kerigma palestinense” (118). Según Hengel, la preexistencia y la mediación en la creación son

(113) Un artículo de Martin Hengel, de más de 100 páginas, concluye así: "Theologically this creed [la sessio ad dexteram de Sal 110, 1], which goes back to the earliest beginnings, is a basic presupposition of the christological reflection and of the development of creeds within the early Church, a presupposition which is given much too little attention in theological investigation. It is the

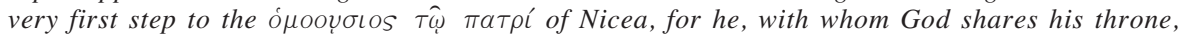
must also be 'equal with God' (Phil 2:6)", M. Hengel, 'Sit at My Right Hand'. The Enthronement of Christ at the Right Hand of God and Psalm 110, 1, p. 225.

(114) Cf. J.G. Gibbs, Creation and Redemption. A Study in Pauline Theology, p. 61; O. Cullman, Cristología del Nuevo Testamento, p. 324.

(115) M. Hengel, Hymns and Christology, p. 95.

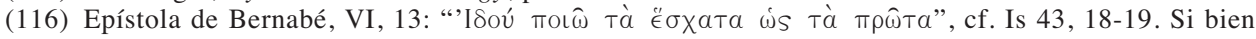
este texto es muy posterior al NT, de todos modo refleja una mentalidad que estaba bien presente en el judaísmo del s. I.

(117) M. Hengel, El Hijo de Dios, p. 100.

(118) J.G. Gibbs, Creation and Redemption. A Study in Pauline Theology, p. 71. El cántico de Flp 2 muestra que muy rápidamente se va del testimonio del acontecimiento, es decir, la humillación y resurrección, hasta el fundamento de este acontecimiento, es decir, la preexistencia. La exaltación del Humillado solo se comprende si tiene como fundamento la preexistencia. En este proceso, la doctrina judía de la Sabiduría preexistente jugó un rol protagónico. "The develop- 
consecuencia de la entronización del Hijo a la diestra del Padre, puesto que "no hay ninguna revelación, ningún hablar ni ningún hacer de Dios que haya podido ocurrir sin el Hijo o prescindiendo de Él” (119).

\section{Relevancia universal del Encarnado}

Esta primera cristología eclesial proclama que la relevancia única y universal de Jesucristo se manifiesta no en el Logos eterno sino en el Logos encarnado, es decir, en Jesús de Nazaret, el Hijo de María, muerto y resucitado (120). Es el Encarnado el que dice "nadie conoce al Padre sino el Hijo, y aquel a quien el Hijo se lo quiera revelar" $(Q 10,22)$; todo ha sido hecho por medio de Aquel que se hizo carne (Jn 1); el Primogénito de la creación es el primer resucitado de entre los muertos (Col 1); el Mediador único es "Cristo Jesús hombre”, que se entregó a sí mismo por todos (1Tim 2); por ello se doblará la rodilla en el cielo, en la tierra y en el abismo ante "Jesús", aquel que se vació obedeciendo hasta la muerte, y muerte de cruz (Flp 2); y el Señor "por medio del cual son todas las cosas, y nosotros por medio de él”, es "Jesús” (1Co 8,6). Esta insistencia muestra que para afirmar la verdad de la encarnación es crucial mantener el vínculo entre lo unversalmente válido y la historia en Jesús de Nazaret.

\section{Significado de la teología de la creación}

Sorprende la rapidez con que, todavía en ambiente palestinense, se vincula la obra salvífica del Jesús exaltado con su participación en la obra de la creación. Esto manifiesta la estrecha unidad, propia de la teología del AT, entre salvación y creación (121). La universalidad soteriológica exige la universalidad creacional. La mediación salvífica única, definitiva y universal en la obra de la salvación reclama una particular atención a la creación, pues Aquel por medio del cual han sido salvadas todas las cosas debe también ser Aquel por medio del cual han sido creadas todas las cosas. Queda claro, entonces, que la preocupación cosmológica está genuinamente motivada por la soteriología y, por ello, no debe mirarse con sospecha, como

ment of cosmic Christology, which appears at an early stage here, does not need to be explained by reference to external stimulus", ibidem, p. 72. Otros textos que posiblemente transmiten fragmentos de himnos cristianos primitivos son 1Pe 3, 18.22; Ef 1, 20-22; Rm 8, 34; 1Tm 3, 16; Heb 1, 3-4; Heb 2, 8-9; Ap 5, 9-10. Estos textos que provienen de tradiciones diversas coinciden en ciertas líneas maestras de su contenido: muerte sacrificial de Jesús, glorificación a la diestra del Padre, relevancia salvífica universal de Jesús. Estos elementos comunes están relacionados con Sal 110 y Sal 8, lo que confirma el protagonismo de la interpretación cristológica de los salmos en el desarrollo de los himnos a Cristo y, por tanto, de la cristología, cf. M. Hengel, Hymns and Christology, pp. 78-96.

(119) M. Hengel, El Hijo de Dios, pp. 100-101.

(120) Algunos teólogos, como P. Knitter, para facilitar el diálogo interreligioso, concentran el carácter único y definitivo en la Sabiduría divina desvinculada de Jesús de Nazaret, haciendo posible que esta misma Sabiduría se haga igualmente presente en otras religiones, cf. M. de França Miranda, Jesucristo y el diálogo de las religiones, pp. 113-115; P. Knitter, Jesús y otros salvadores, Theologica Xaveriana 46 (1996), pp. 127-140.

(121) "Con palabras de Barth: se reconoce que la creación es el fundamento extrínseco de la alianza porque la alianza es es fundamento intrínseco de la creación” (cf. KD III, 1, 103ss, 258s.), W. Kern, Interpretación teológica de la fe en la creación, en MySal II, Madrid 1977, p. 388. 
si se tratara de una invasión griega en la teología cristiana. En este proceso pudieron haber jugado un papel importante las especulaciones judías sobre la sabiduría preexistente, y algunas palabras de Jesús, tales como los dichos $\hat{\eta} \lambda \theta$ ov (122), que leídos a la luz de la resurrección adquirieron un significado más amplio.

Sin el recurso a la teología de la creación, el Evangelio se vuelve sectario, pues no puede dar razón de la totalidad, y no podría sino moverse en el registro fideísta de: “cree si quieres salvarte o márchate”, según la expresión que Celso atribuye a los predicadores callejeros cristianos (123). Solo si se involucra la creación, el mensaje cristiano puede aspirar a ser universalmente válido, pues el carácter crístico de toda la creación manifiesta que toda la realidad está vinculada a Cristo y que, por tanto, Cristo no es ajeno a la realidad sino su origen y meta, dado que hay "un solo Señor, Jesús Cristo, por medio del cual [son] todas las cosas y nosotros por medio de él” (1Co 8, 6). De ahí que la creación es rà ísıa (Jn 1, 11). Solo vinculando soteriología con protología se puede pensar, con radicalidad, la relevancia universal de la obra histórica de Jesús.

Los textos bíblicos que vinculan a Cristo con el opus proprium Dei de la creación, que podrían parecer los más particularistas, son, en realidad, el fundamento de las afirmaciones más radicalmente universalistas. Por ello, a propósito de la teología paulina de la misión, un comentarista afirma: "Lo que encontramos en Pablo podría ser definido como un acceso universal a una comunidad particularista" (124). Efectivamente, en el cristianismo se da lo que podríamos paradójicamente llamar un particularismo universalista, puesto que está construido a partir de una revelación histórica que se apoya en una determinada teología de la creación. Nada, entonces, queda excluido del influjo de Cristo: la realidad total está fundada protológicamente en Cristo, ha sido iluminada en la plenitud de la historia y, por tanto, toda ella abriga una esperanza escatológica, también en Cristo.

¿Hay relación entre la el universalismo misionero y la convicción de que Cristo ha participado en la obra universal de la creación?, ¿qué concepto depende de cuál? Ciertamente, desde el punto de vista ideológico, la mediación universal en la creación y la misión universal se corresponden. Pero no parece legítimo pretender una relación causa/efecto entre estos conceptos. Al parecer, los textos no permiten describir la génesis de estas ideas. Hay que recordar que "al inicio no hubo un desarrollo bastante rápido de la cristología, sino una explosión” (125). En todo caso, desde el punto de vista histórico, la relevancia salvífica universal de Jesús es el fundamento tanto de la misión universal como de la reflexión acerca de participación de Cristo en la obra de la creación.

(122) Cf. E. Arens, The H $\Theta O N$ Sayngs in the Synoptic Tradition, Göttingen 1976. Se trata de los logia en que Jesús declara "yo he venido", cf. Mc 2, 17; 10, 45; Mt 10, 34; 5, 17; Lc 12, 49; 19, 10.

(123) Cf. Contra Celso, VI, 11: "Si unos -refiriéndose a los cristianos-proclaman a uno y otros a otros, y todos tienen a la mano como un santo y seña: "Cree si quieres salvarte, o márchate"

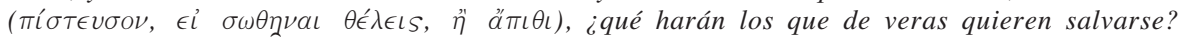
¿Tendrán que tirar los dados al aire para adivinar adónde hayan de volverse y a quién adherirse?".

(124) W.P. Bowers, art. G.F. Hawthorne - R.P. Martin - D.G. Ried (Eds.), voz Mission en Dictionary of Paul and his Letters, p. 615.

(125) M. Hengel - A.M. Schwemer, Paul, Between Damascus and Antioch. The Unknown Yeares, Kentucky 1997, pp. 283-284. 
La universalidad de la obra de Cristo tiene consecuencias para la comprensión del ser de las cosas. El fundamento de esta soteriología de proporciones universales se encuentra en el ser de las cosas, que "han sido hechas por medio de Él” (Jn 1,3). El carácter cristológico de la creación implica una pregunta por la totalidad que vincule el ser de Cristo con el ser de la creación. De este modo, así como la antropología teológica afirma homo capax Dei, la teología del mundo puede afirmar creatio capax salutis.

\section{Cristología funcional y cristología ontológica}

Tal como la soteriología supone una cosmología, y las reflexiones acerca de la teología de la creación se revelan como la consecuencia necesaria del significado universal de la obra del Señor Jesús, así también la soteriología supone una cristología que no solo se interrogue sobre las "funciones" sino también sobre el "ser" de Cristo, pues la "función salvífica" supone una "persona salvífica” y, por tanto, la soteriología debe buscar su fundamento en el ser de Cristo (126). La función salvífica universal, única y definitiva de Jesús exige una reflexión sobre el "ser" de Jesús, que justifique su significado salvífico universal, único y definitivo. Una cristología solo de funciones no hace justicia a los enunciados del Nuevo Testamento.

Esta búsqueda del fundamento ontológico de las funciones del Salvador la encontramos incipiente en los sinópticos ("¿Quién es este que hasta el viento y el mar le obedecen?", Mc 4, 41), en marcha en el Evangelio de Juan (127), que va de fórmulas funcionales a fórmulas de unidad esencial ( YYo y el Padre somos uno", Jn 10, 30), y plenamente desarrollada en la posterior cristología de los concilios (128). Según Martin Hengel, "el elemento nuevo en la más tardía cristología del Logos y del desarrollo que condujo a la formación de las doctrinas en la Iglesia primitiva fue que hubo una preocupación por poner de acuerdo 'las funciones divinas' del Hijo de Dios con la conceptualización y los modelos de pensamiento de la metafísica griega del ser" (129).

(126) Cf. R. Schnackenburg, La persona de Jesucristo reflejada en los cuatro evangelios, p. 322 . Es posible una reflexión análoga acerca de la relación entre el sentido de envío y la identidad de Jesús.

(127) A propósito del evangelio de Juan, R. Schnackenburg afirma: "La unidad funcional del Hijo con el Padre se expresa en Jn 5, 19: El Hijo no puede hacer nada por sí, si no lo ve hacer al Padre; porque lo que este hace, lo hace igualmente el Hijo. Pero las fórmulas de unidad: 'Yo en el Padre y el Padre en mí' (Jn 14, 10-11.20; cf. 17, 21-23) o 'Yo y el Padre somos uno' (Jn 10, 30) parecen sobrepasar esta cooperación y remitir a una unidad esencial original entre el Padre y el Hijo. En el Hijo está presente el Padre, sin identificarse con él. J.D.G. Dunn habla de una 'especie de identidad del ser', , La persona de Jesucristo reflejada en los cuatro evangelios, p. 360; J.D.G. Dunn, Let John be John, en P. Stuhlmacher (Ed.), Das Evangelium und die Evangelien, WUNT 28, Tübingen 1983, p. 329.

(128) "En el siglo siguiente y subsiguiente al Evangelio de Juan, los cristianos comenzaron a apropiarse y a adaptar términos y categorías conceptuales de la tradición filosófica griega (así, 'ser' [ousía], 'esencia' [hypóstasis, lat. substantia]). Pero, tal vez, no es excesivo sugerir que el uso joánico de la tradición del Nombre divino es, en sus propios términos, una afirmación radical y directamente equivalente acerca de la vinculación de Jesús a Dios”, L.W. Hurtado, Lord Jesus Christ. Devotion to Jesus in Earliest Christianity, Eerdmans 2003, p. 385.

(129) M. Hengel, Christology and New Testament Chronology, p. 40. 
La pretensión de validez universal de la obra de Jesús de Nazaret pertenece, entonces, a la primera cristología que podemos observar. La rapidez con que ella se constituyó no nos permite documentar una cristología sin alcance universal. Desde el punto de vista de la lógica interna de la doctrina, es muy razonable pensar en una etapa inicial en que, a partir de la entronización de Jesús a la diestra del Padre (Sal $110,1)$, se proclame el carácter universal de la obra redentora de Dios en Jesús y, de allí, reflexione sobre el ser de Jesús y su significado cosmológico. Sin embargo -repitámoslo-, los documentos disponibles no nos permiten reconstruir una cristología, por incipiente que sea, que no tenga pretensión de validez universal, y esta validez universal tiene su fundamento en la existencia histórica de Jesús de Nazaret.

Iesus, capax Dei?

La pretensión universal del acontecimiento histórico de Jesús de Nazaret es el punto decisivo de nuestro estudio. Ya se ha visto exegéticamente que la primera cristología ya reclama validez universal, y que esta pretensión está bien fundada en la vida de Jesús mismo.

Entonces, ¿puede un acontecimiento histórico pretender valor universal? El problema de Celso y Lessing solo se resuelve de modo positivo si efectivamente el Logos universal y el Jesús histórico coinciden efectivamente en un único sujeto. Esta afirmación pone de relieve la necesidad de una correcta comprensión de la unión hipostática. No se trata de una yuxtaposición o de una mezcla, sino de una verdadera unión. Las controversias cristológicas de los primeros siglos nos iluminan: Se debe evitar el monofisismo que, por asegurar la unión, diluye lo histórico y, a la vez, rechazar el nestorianismo que, en favor de la autonomía de lo histórico, no logra expresar la unidad entre estas realidades en el único sujeto. Los adverbios de la fórmula de Calcedonia insisten en que la unión es sin confusión, sin cambio, sin división, sin separación. Por ello, cualquier cristología que debilite, en Jesucristo, la integridad de su humanidad (docetismo o monofisismo) o la integridad de su divinidad (ebionismo o adopcionismo), o que sea incapaz de expresar la verdad de su unión en un único sujeto (nestorianismo), no hará justicia al Nuevo Testamento y hará inaceptable el significado universal de lo histórico.

Ahora bien, tal como ya se ha dicho, para que la comprensión eclesial de Jesús sea legítima e históricamente comprensible, ella debe estar fundada en la autocomprensión propia de Jesús de Nazaret.

Entonces, nos preguntamos: Iesus capax Dei?, es decir, ¿la filiación divina fue una realidad accesible a Jesús de Nazaret, en el sentido de ser, de algún modo, humanamente comprensible?, ¿era accesible a Jesús su propia identidad divina?, ¿era Jesús, en su humanidad, capaz de ser portador de la plenitud de la divinidad? La verdad de la encarnación exige una respuesta positiva (130), es decir, Jesús en su

(130) “La unión hipostática, vista desde Dios, es la autocomunicación del ser absoluto de Dios, tal y como subsiste en el Logos, a la naturaleza humana de Cristo en cuanto sustentada por él hipostáticamente”, K. Rahner, Ponderaciones dogmáticas sobre el saber de Cristo y su consciencia de sí mismo, en Escritos de Teología V, Madrid 1967, pp. 233 (tomo la traducción española de O. González de Cardedal, Cristología, Sapientia fidei 24, Madrid 2001, p. 467). 
humanidad se autocomprendió como el Hijo único de Dios (afirmamos el "hecho" sin intentar explicar el "modo") (131). En caso contrario, ¿qué sentido tendría afirmar la presencia de Dios en la historia si esta presencia no es accesible al hombre, que es histórico? Si la plenitud de la divinidad es inaccesible al Maestro de Galilea, entonces, se vulnera la verdad de la encarnación, porque Dios no estaría realmente presente, pues no estaría presente para el hombre. Pero si el Galileo es verdaderamente capaz de acoger la autocomunicación de Dios, entonces, la naturaleza humana de Jesús de Nazaret, históricamente limitada y culturalmente condicionada, realmente es capax Dei. Por ende, la humanidad de Jesús, que solo puede ser concebida histórica y culturalmente situada, se revela capaz de sostener y expresar un significado universal, único y definitivo.

\section{Historia, capax Dei?}

Afirmar que la realidad histórica de Jesús de Nazaret es portadora de un significado universal, único y definitivo, equivale a decir que lo culturalmente condicionado (la humanidad del Hijo) es capaz de portar y expresar lo universalmente válido (la divinidad del Hijo), pues ambas realidades coinciden porque están unidas hipostáticamente, es decir, en una única persona.

Decir Iesus capax Dei, en toda su radicalidad, equivale a afirmar que la naturaleza humana, en todo su carácter limitado e histórico, es capax Dei. Así, nuestra propia humanidad -que es la misma de Jesús- se ha revelado capaz de portar la autocomunicación definitiva de Dios, que tiene alcance universal, único y definitivo.

Si el lenguaje de la autocomunicación definitiva de Dios fue accesible a Jesús de Nazaret, en su humanidad, entonces, el lenguaje humano en general, siempre culturalmente situado, es capaz de portar en sí lo universalmente válido. El idioma del hombre tiene la capacidad de "decir la plenitud de la divinidad". Entonces, la experiencia de Jesús es expresable y, por ello, transmisible a la familia humana.

Solo tienen sentido los enunciados cristológicos del Nuevo Testamento, y el Nuevo Testamento en sí, si la autocomunicación de Dios al hombre en Jesús, de algún modo, es accesible al propio Jesús y, por medio de él, a toda la familia humana. Así se puede afirmar un significado definitivo y universal a la revelación histórica, y se comprende la precisión y la agudeza de la expresión de Tertuliano referida a la carne de Cristo: “caro salutis est cardo” (Res., VIII, 2).

(131) Según K. Rahner, la vissio immediata es consecuencia necesaria de la unio hypostatica. Es decir, una unión hipostática que no implique la conciencia de sí es metafísicamente irrealizable. Naturalmente, una cosa es afirmar el "hecho" de la visión inmediata y otra explicar el "modo". Hay aquí un amplio espacio para el trabajo teológico: son luminosas las distinciones de Rahner y otros entre categorial y trascendental; kenótico y glorioso; temático y atemático; objetual y fundamental, etc. Cf. K. Rahner, Ponderaciones dogmáticas sobre el saber de Cristo y su consciencia de sí mismo, en Escritos de Teología V, pp. 232-233; H.U. v. Balthasar, La conciencia de Cristo, en Puntos centrales de la fe, Madrid 1985, pp. 131-144; Ch. Schönborn, Dios ha enviado a su Hijo. Cristología, Valencia 2006, pp. 148-172; O. González de Cardedal, Cristología, pp. 458-472; Comisión Teológica Internacional, La conciencia que Jesús tenía de sí mismo y de su misión (1985), Documentos 1969-1996, Madrid 2000, pp. 377-391. 
Dios se da a sí mismo, humanamente, en la historia de Jesús de Nazaret. No solo "se manifiesta" sino que "se da", es decir, algo acontece. De este modo, Jesucristo "no es solo la manifestación, sino también la realización histórica del amor incondicional de Dios hacia la humanidad” (132). El carácter fáctico y no solo epifánico muestra el carácter definitivo, y por ello único y de alcance universal, del acontecimiento que se realizó una vez y para siempre en Jesús de Nazaret

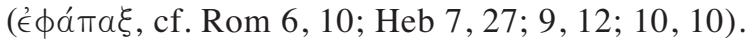

En síntesis, la unión hipostática permite afirmar la validez universal de Jesús y de la historia. El acontecimiento histórico de la encarnación es, entonces, una prueba a posteriori de que la carne, de hecho, es capaz de portar la plenitud de la divinidad históricamente (cf. Col 2,9).

\title{
RESUMEN
}

El artículo busca abordar históricamente la siguiente pregunta: ¿Cuál es el origen y alcance de la pretensión cristiana que proclama a Jesús de Nazaret como Salvador único, universal y definitivo? Para ello, hace un recorrido retrospectivo, que parte desde el cristianismo preniceno y luego se adentra en el Nuevo Testamento, partiendo por los documentos más recientes y luego avanzando desde lo prepaulino hasta llegar a Jesús mismo. De este modo, se muestra que la pretensión de universalidad del cristianismo, está presente desde sus orígenes y hunde sus raíces en el mismo Jesús de Nazaret. Luego se pasa a una elaboración sistemática de los datos, insistiendo en la relevancia teológica de la vinculación entre cristología y creación, y en la necesidad de una recta comprensión de la unión hipostática para poder afirmar el significado único, universal y definitivo de la revelación histórica del Hijo de Dios.

Palabras clave: Cristología primitiva, Homo capax Dei, Jesús histórico, Teología de la Creación.

\begin{abstract}
The author of this article attempts to approach in an historical fashion the following question: What is the origin and extension of the Christian proposition, which proclaims Jesus of Nazareth as a unique, universal and definitive Savior? To answer this, the author takes a retrospective path, starting with pre-Nicene Christianity and then delving into the New Testament, beginning with the more recent documents and later continuing on from the prePauline texts and arriving at Jesus himself. In this way, Christianity's proposition of university is shown to be present from its origins, and finds its roots in Jesus of Nazareth himself. Then the author goes on to a systematic elaboration of data, insisting upon the theological relevance of linking Christology and Creation, as well as upon the necessity of a correct comprehension of the hypostatic union, in order to affirm the unique, universal and definitive significance of the historical revelation of the Son of God.
\end{abstract}

Key words: Primitive Christology; Homo capax De;, Historical Jesus; Creation Theology.

(132) M. de França Miranda, Jesucristo y el diálogo de las religiones, p. 123. 